\title{
LAS CLÁUSULAS DE CONFIDENCIALIDAD EN EL CONTRATO DE TRABAJO*
}

[Confidentiality Clauses in the Contract of Employment]

\author{
Alfredo Sierra Herrero** \\ Universidad de los Andes, Santiago de Chile
}

\begin{abstract}
Resumen
Quienes se familiarizan normalmente con la información confidencial de una empresa son sus trabajadores, en particular, aquellos que tienen el carácter de exclusiva confianza. Para resguardar el cuidado de dichos antecedentes, la empresa suscribe con dichos trabajadores cláusulas de confidencialidad en los con-
\end{abstract}

\begin{abstract}
Employees, especially those in exclusively confidential positions, are the usually familiar with the company's confidential information. In order to safeguard that information, the company incorporates confidentiality clauses in the contracts of employment of said employees. This article analyzes said clauses
\end{abstract}

RECIBIDo el 11 de noviembre y ACEPTADo el 13 de diciembre de 2013

* La redacción del presente artículo ha contado con la ayuda del Fondo Nacional de Ciencia y Tecnología de la República de Chile, en el marco del Proyecto FondeCYT regular $\mathrm{N}^{\circ} 1130664$, titulado: "Régimen laboral de gerentes y personal directivo de exclusiva confianza”, en el cual el autor es investigador responsable. Éste agradece la valiosa colaboración del licenciado en Ciencias Jurídicas y Sociales de la Universidad de Chile, Sr. Ignacio Araya Paredes, en su calidad de ayudante de investigación del presente proyecto.

${ }^{* *}$ Licenciado en Ciencias Jurídicas y Sociales por la Universidad de Chile. Doctor en Derecho por la Universidad de Santiago de Compostela. Profesor de Derecho del Trabajo en la Universidad de los Andes. Dirección postal: Mons. Álvaro del Portillo 12.455, Las Condes, Santiago, Chile. Correo electrónico: asierra@uandes.cl 
tratos de trabajo. Este artículo analiza tales cláusulas en el ámbito jurídico laboral, en particular, su noción, objetivos principales, requisitos necesarios para que sean consideradas válidas y las consecuencias que se derivan de su incumplimiento.

Palabras Clave

Contrato de trabajo - Derechos del trabajador - Cláusula de confidencialidad - Secreto empresarial. in the legal-labor scope, particularly their notion, their main objectives, required to be deemed as valid, and the consequences of non-compliance.

\section{KEYWORDS}

Contract of Employment- Labor rights - Confidentiality Clause - Trade Secret.

\section{INTRODUCCIÓN}

La fuerza competitiva de las empresas está vinculada, en una gran dimensión, a sus capacidades y habilidades para generar y manejar información y conocimientos tecnológicos y comerciales ${ }^{1}$. En este contexto, la información se ha convertido en un factor de riqueza, y sus creadores o quienes tienen acceso a ella gozan de ventajas comparativas en relación con aquellos que no disponen de esta posibilidad ${ }^{2}$.

Así pues, la información de naturaleza confidencial tiene una importancia clave en el éxito de una empresa. Existen diversos estudios empíricos que dan cuenta de que hoy buena parte del valor final de los productos y servicios que los operadores comercializan y ofrecen en el mercado reside en los intangibles $y$, especialmente, en antecedentes secretos de carácter empresarial ${ }^{3}$. Tales antecedentes se constituyen en muchos casos en elementos de la individualidad de una empresa, cuya utilización se manifiesta en una mejor producción, en una disminución de costos y tiempos, y en un aumento de calidad y venta de los productos y servicios ${ }^{4}$.

Por tales motivos, no debe extrañar que las empresas conciban esta clase de información como un activo valioso, y que se esfuercen en mantener a

\footnotetext{
${ }^{1}$ Mitelman, Carlos - Zuccherino, Daniel, Protección jurídica de la información confidencialy de datos cientificos (Buenos Aires, LexisNexis, 2007), p. 1.

${ }^{2}$ Ibíd.

${ }^{3}$ Suñol Lucea, Aurea, El secreto empresarial. Un estudio del articulo 13 de la ley de competencia desleal (Pamplona, Thomson Reuters, 2009), p. 27.

${ }^{4}$ Mitelman, C. - Zuccherino, D., cit. (n. 1), pp. 17-18.
} 
resguardo de quienes pretendan conocerla sin sufragar los costes de su producción, adquisición o descubrimiento5.

Ciertamente, el mecanismo jurídico más utilizado con miras a proteger dicho secreto es el pacto o cláusula de confidencialidad. Las empresas lo suelen suscribir con aquellas personas con las que mantienen una relación comercial o laboral y que, producto de esa relación, pueden acceder a antecedentes confidenciales de ella. Si existen quienes se familiarizan con información reservada de manera habitual en una empresa, éstos son precisamente sus trabajadores. En particular, aquellos que se sitúan en una posición cercana al empleador dentro de la organización interna de la empresa, como son los gerentes o apoderados dotados de poderes generales y los trabajadores de exclusiva confianza. Justamente, el empleador confía en ellos dicha información pues resulta necesaria para que éstos puedan cumplir de buena forma la labor para la que fueron contratados.

En el presente artículo pretendemos analizar dichas cláusulas. En la primera parte, veremos qué se entiende por secreto de empresa en general y cómo se encuentra regulado en nuestra legislación. En la segunda parte, nos centraremos en las cláusulas de confidencialidad propiamente tales, en específico su noción y principales objetivos. En la tercera parte, analizaremos, a luz del principio de proporcionalidad, los requisitos necesarios para que este tipo de pactos sean considerados válidos y no sean contrarios a los derechos fundamentales de libertad de trabajo y la libertad de expresión. Finalmente, en la cuarta parte, examinaremos las consecuencias que se derivan en caso de que un trabajador incumpla el deber de reserva, principalmente el despido por falta de probidad y la indemnización por daños y perjuicios.

\section{SOBRE EL SECRETO DE EMPRESA Y SU PROTECCIÓN LEGAL}

El secreto es un estado de hecho o situación fáctica consistente en el conjunto de antecedentes que una persona o personas tienen sobre la existencia o caracteres de cosas, procedimientos, hechos, etc. y que desean conservar en exclusiva frente a otras personas ${ }^{6}$.

El ordenamiento jurídico protege diferentes secretos porque su titular tiene determinado interés en mantenerlo en reserva. En este sentido, conforme con Gómez Segade, según si el titular sea la administración pública (en un sentido amplio) o un particular, cabe distinguir entre secretos oficiales y

${ }^{5}$ Suñol Lucea, Aurea, cit. (n. 3), p. 159.

${ }^{6}$ Gómez Segade, José Antonio, El secreto industrial. Concepto y protección (Madrid, Tecnos, 1974), p. 43. 
secretos privados ${ }^{7}$. Entre los primeros destacan por su importancia los que tienen por objeto la economía del país y su sistema de defensa ${ }^{8}$.

En cambio, secretos privados son aquellos que responden a un interés jurídicamente apreciable de un particular. Pueden relacionarse así con variados aspectos de la actividad humana: desde una cuestión íntima como escribir una carta hasta la gestión de una empresa o establecimiento industrial ${ }^{9}$. Con todo, se excluye como secreto industrial y de negocios a la información que sea del dominio público o la que resulte evidente para un técnico en la materia con base a antecedentes previamente disponibles ${ }^{10}$.

Tratándose de una empresa, la información sensible se circunscribe más bien a cuestiones propias del negocio. En este orden, se utiliza la expresión "secreto de empresa" para hacer referencia a esta clase de información. Siguiendo a Gómez Segade, es posible distinguir tres grupos de secretos: $i$ ) Secretos técnicos industriales: aquellos que consisten en procedimientos de fabricación, reparación o montaje, y prácticas manuales para la puesta a punto de un producto; ii) Secretos comerciales: aquellos que consisten en listas de clientes, de proveedores, cálculo de precios, etc.; y iii) Secretos sobre organización interna: aquellos que consisten en relaciones con el personal de la empresa, situación financiera de la empresa, el proyecto de celebrar un contrato, etc ${ }^{11}$.

En nuestro país, la Ley $N^{\circ}$ 19.039: sobre Propiedad industrial, dedica su título $8^{\circ}$ a la protección del secreto empresarial. De acuerdo con dicho cuerpo legal, este secreto se define como "todo conocimiento sobre productos o procedimientos industriales, cuyo mantenimiento en reserva proporciona a su poseedor una mejora, avance o ventaja competitiva" (artículo 86). Según se aprecia, la norma hace referencia solamente a "productos o procedimientos industriales". Por procedimientos industriales es posible entender el "conjunto de operaciones materiales ejecutadas para la obtención, transformación o transporte de uno o varios productos naturales"12; y el producto industrial sería el resultado que se obtiene de la aplicación de dicho procedimiento.

Como se advierte, esta definición legal sólo comprende dentro del concep-

${ }^{7}$ Ibíd., p. 45.

${ }^{8}$ Ibíd., p. 46.

${ }^{9}$ Ibíd., p. 46.

${ }^{10}$ Salgado Miranda, Jorge, La cláusula de confidencialidad en el contrato individual de trabajo (Quito, tesis para optar al grado de Doctor en Derecho, Universidad Internacional SEK del Ecuador, 2006), p. 24

${ }^{11}$ Gómez Segade, José Antonio, cit. (n. 6), pp. 51-52.

${ }^{12}$ Diccionario de la Lengua Española (22a edición [disponible en línea: http://lema. rae.es/drae/?val=industria, fecha de consulta: 2 de noviembre de 2013], s.v. "industria”, $2^{\mathrm{a}}$ acepción 
to de secreto de empresa a aquellos secretos técnicos-industriales de los que hablaba Gómez Segade. Esta definición, restringida a aspectos "industriales" y no a otros antecedentes empresariales que pueden también ser reservados obedece, según Schmitz Vaccaro, precisamente "al hecho de que el tema sea regulado por la ley de propiedad industrial” ${ }^{\prime 3}$.

A este respecto, cabe tener en cuenta algunas normas de nuestro ordenamiento jurídico que se refieren al carácter confidencial de determinadas informaciones o antecedentes, a saber:

i) El artículo 154 de la Ley general de bancos (texto refundido por el Decreto con fuerza de ley $\mathrm{N}^{\circ} 3$, del Ministerio de Hacienda, de 1997) a cuyo tenor "los depósitos y captaciones de cualquiera naturaleza que reciban los bancos están sujetos a secreto bancario y no podrán proporcionarse antecedentes relativos a dichas operaciones sino a su titular o a quien hay a sido expresamente autorizado por él o a la persona que lo represente legalmente". Luego, destaca la misma disposición: "Las demás operaciones quedan sujetas a reserva y los bancos solamentepodrán darlas a conocer a quien demuestre un interés legitimo y siempre que no sea previsible que el conocimiento de los antecedentes pueda ocasionar daño patrimonial al cliente" (artículo 154 inciso $1^{\circ}$ ). Cabe señalar, sin embargo, que nuestro ordenamiento reconoce diversos supuestos en que se puede levantar el secreto bancario ${ }^{14}$.

ii) El inciso $1^{\circ}$ del artículo 85 de la Ley $\mathrm{N}^{\circ} 18.045$, de Mercado de valores señala que a "los socios, administradores, y en general a cualquier persona que en razón de su cargo o posición tenga acceso a información reservada de las sociedades clasificadas, se les prohibe valerse de dicha información para obtener para si o para otros, ventajas económicas de cualquier tipo"15.

iii) Tratándose de información privilegiada en el mercado de valores, el artículo 165 de la Ley 18.045 dispone que: "cualquier persona que en razón

${ }^{13}$ SchmitzVaccaro, Christian, Protección del secreto empresarial, en ContreRAS, Rodrigo (coordinador), Jornadas Chileno-Uruguayas de Derecho Comercial (Santiago de Chile, Librotecnia, 2011), p. 88.

${ }^{14}$ Así, p. ej., el artículo 154 incisos $4^{\circ}$ y $5^{\circ}$ de la Ley general de bancos; el artículo 1 inciso $3^{\circ}$ del Decreto con fuerza de ley $\mathrm{N}^{\circ} 707$; los artículos 19 y 236 CPP.; el artículo 2 letra b) de la Ley $\mathrm{N}^{\circ}$ 19.913; y los artículos. 62 y 62 bis CTrib. Este último cuerpo legal fue objeto de diversas modificaciones sustantivas, en lo relativo al levantamiento del secreto bancario, por la Ley $\mathrm{N}^{\circ} 20.406$, de 5 de diciembre de 2009, que: Establece normas que permiten el acceso a la información bancaria por parte de la autoridad tributaria.

${ }^{15}$ Con la aprobación de las tres cuartas partes de los directores en ejercicio podrá darse el carácter de reservado a ciertos hechos o antecedentes que se refieran a negociaciones aún pendientes que al conocerse puedan perjudicar el interés social. Tratándose de emisores no administrados por un directorio u otro órgano colegiado, la decisión de reserva debe ser tomada por todos los administradores (cfr. inciso $3^{\circ}$ artículo 10 de la Ley $\mathrm{N}^{\circ} 18.045$ ). 
de su cargo, posición, actividad o relación con el respectivo emisor de valores [...], posea información privilegiada, deberá guardar reserva y no podrá utilizarla en beneficio propio o ajeno, ni adquirir o enajenar, para sí o para terceros, directamente o a través de otras personas los valores sobre los cuales posea información privilegiada". El artículo 166 del mismo cuerpo legal establece una serie de presunciones de conocimiento de información privilegiada.

iv) El artículo 10 de la Ley $\mathrm{N}^{\circ} 19.628$, sobre Protección de la vida privada, dispone que no pueden ser objeto de tratamiento, en registros o bancos de datos de organismos públicos o por particulares, los antecedentes sensibles de una persona. Estos antecedentes consisten en "aquellos datos personales que se refieren a las características físicas o morales de las personas o a hechos o circunstancias de su vida privada o intimidad, tales como los hábitos personales, el origen racial, las ideologías y opiniones politicas, las creencias o convicciones religiosas, los estados de salud físicos o psíquicos y la vida sexual" [cfr. artículo 2 letra g) Ley 19.628] ${ }^{16}$.

v) El artículo 22 inciso $8^{\circ}$ del Decreto-ley $\mathrm{N}^{\circ} 211$, a propósito de la prueba que se puede rendir en un juicio de libre competencia, contempla que se le puede dar el carácter de reservado -respecto de terceros, e incluso de las demás partes del proceso- a "aquellos instrumentos que contengan fórmulas, estrategias o secretos comerciales o cualquier otro elemento cuya revelación pueda afectar significativamente el desenvolvimiento competitivo de su titular".

Según se observa, hay información que posee el carácter de reservada que no necesariamente se incardina dentro del secreto de empresa de la Ley $\mathrm{N}^{\circ}$ 19.039, que, como se explicó, se encuentra circunscrito a aspectos industriales. En efecto, existen disposiciones legales que otorgan de manera imperativa el carácter de secreto a materias que se refieren a aspectos íntimos de las personas (Ley sobre protección de la vida privada), a las cuentas bancarias (Ley general de bancos), o a la información privilegiada en el mercado de valores (Ley de mercado de valores). Se trata de normas cuyo cumplimiento se dirige principalmente a empresas que manejan bases de datos, bancos, sociedades clasificadas y emisores de valores, los cuales deberán velar por el cumplimiento de dicha reserva. Conviene subrayar que, entre los principales obligados a no divulgar tal clase de información, se encuentran los dependientes de dichas

\footnotetext{
${ }^{16}$ Sobre los datos personales sensibles, véase: Bertelsen Repetto, Raúl, Datos personales: propiedad privada, libre iniciativa particular y respeto a la vida privada, en WaHL, Jorge (editor), Tratamiento de datos personales y protección de la vida privada. Estudios sobre la Ley $N^{\circ} 19.628$ sobre protección de datos de carácter personal (Santiago de Chile, Cuadernos de Extensión Jurídica, 5, Facultad de Derecho, Universidad de los Andes, 2001), pp. 127 ss.
} 
entidades. Es por ello que suele ser habitual que sus contratos de trabajos contemplen el deber de reserva respecto de los secretos antes mencionados ${ }^{17}$.

Asimismo, se puede conceder a petición de parte el carácter de reservado -en un proceso de libre competencia- a aquellas informaciones o circunstancias cuya revelación pueda afectar negativamente el interés competitivo de su titular (Decreto-ley $N^{\circ} 211$ ). Debe tratarse de aspectos cuyo secreto procura a éste una ventaja con relación a sus competidores. De esta forma, si la información es traspasada a empresas competidoras, la empresa titular dejaría de poseer esa ventaja, con lo cual indudablemente sufriría un perjuicio.

Por último, en el ámbito penal, se encuentra específicamente tipificado el delito de revelación de secretos de fábrica, para todo aquel que de manera fraudulenta divulga los secretos de la empresa donde ha estado o esté empleado (cfr. artículo $284 \mathrm{CPen}$.); lo que pone de manifiesto la gravedad con que nuestro ordenamiento concibe el traspaso de información reservada.

Como se aprecia, es amplio el espectro de asuntos que por mandato legal o interés competitivo legítimo de la empresa caben dentro del ámbito de la confidencialidad. En esta línea, en el Derecho comparado se ha entendido el secreto de empresa en un sentido amplio. Así, se ha señalado que dicho concepto importa aquella "información de conocimiento reservado que tiene un valor económico derivado de la ventaja comercial que significa, para quien lo posee bajo condición, que sus competidores no lo conozcan también"18. Es decir, se comprenden dentro de este concepto los secretos

${ }^{17}$ Véase, en este sentido, la sentencia de la Corte de Chillán, de 3 abril de 2009, rol $\mathrm{N}^{\circ} 12-2009$.

${ }^{18}$ Castro García, Juan David, La propiedad industrial (Bogotá, Universidad Externado de Colombia, 2009), p. 426. En esta misma línea, Suñol LuceA, A., cit. (n. 3), p. 27, lo define como "todo conocimiento reservado sobre ideas productos industriales o comerciales que el empresario, por su valor competitivo para la empresa desea mantener oculto". Por su parte, Mitelman, C. - Zuccherino, D., cit. (n. 1), p. 4, definen secreto empresarial, como "todo aquel conocimiento que, mantenido en reserva, es útil a una empresa o persona, pues representa una ventaja competitiva en el rubro de la actividad pertinente". Dichos autores dan a conocer una lista de información o conocimientos que potencialmente puede reunir el carácter de confidencial, a saber: $i$ ) Información técnica. Investigación y desarrollo: fórmulas, compuestos, procedimientos, prototipos, apuntes de laboratorio o datos de experimentaciones, reportes de investigación y desarrollo; ii) Información sobre producción: costos de producción u otros datos relativos al proceso de producción; técnicas de manufactura; información sobre maquinaria; iii) Información sobre mercados y ventas: listas de clientes; reportes sobre comercialización y venta; planes de comercialización y venta; iv) Información financiera: presupuestos, pronósticos económicos, información sobre costos, balances, estadísticas; $v$ ) Información administrativa: manuales de políticas corporativas, planes de emergencia, códigos software; véase: Mitelman, C. - Zuccherino, Daniel, cit. (n. 1), p. 5. 
técnicos, industriales, comerciales y de organización interna de la empresa antes mencionados. En definitiva, creemos que pueden presentar el carácter de secreto empresarial, y, por ende, ser protegidas por medio de pactos de confidencialidad las tres categorías de secreto a que hacía mención Gómez Segade.

\section{PACtos De CONFIDENCIALIDAD EN EL CONTRATO DE TRABAjO}

\section{Noción y objetivos.}

Por confidencialidad se entiende "cualidad de confidencial", y por confidencial, "secreto o reservado"19. Secreto se define como "cosa que cuidadosamente se tiene reservada y oculta" y también como "conocimiento que exclusivamente alguien posee de la virtud o propiedades de una cosa o de un procedimiento útil en medicina o en otra ciencia, arte u oficio" ${ }^{20}$. Por su parte, reservado se define como "cauteloso, reacio en manifestar su interior" ${ }^{21}$. De ello se deduce que una obligación de confidencialidad es un deber de custodia de cierta información que sólo es conocida por una persona o por un número limitado de personas, con exclusión de otros. De acuerdo a Cabanellas de las Cuevas, dos son los elementos esenciales para que una información tenga la condición de confidencial. El primer elemento consiste en que los conocimientos se encuentren únicamente en poder de un número limitado de personas; eso sí, no cabe exigir que estos conocimientos secretos sólo sean accesibles a su titular, pues ello impediría su utilización económica, la cual requiere su comunicación a ciertos trabajadores, proveedores, etc. El segundo elemento es de orden subjetivo y consiste en la voluntad de quien lo posee de que éste no sea divulgado. Ciertamente, este deseo se manifiesta de diversas formas tangibles, destacándose entre aquellas de orden jurídico, la imposición de obligaciones de no divulgación o cláusulas de confidencialidad ${ }^{22}$.

Así las cosas, en el ámbito laboral, la cláusula de confidencialidad puede ser definida como un acuerdo bilateral suscrito entre empleador y trabajador, cuyo objeto consiste en imponer a este último la obligación de que determinada información, de la cual tome conocimiento con ocasión de su labor en una empresa, sea mantenida oculta a terceros ${ }^{23}$. Las informaciones que

${ }^{19}$ Moliner Ruiz, María, Diccionario de uso del español (Madrid, Gredos, 2002), p. 720 .

${ }^{20}$ Diccionario, cit. (n. 12), s.v. "Secreto", $1^{\mathrm{a}}$ y $2^{\mathrm{a}}$ acepciones.

${ }^{21}$ Ibíd., s.v. "reservado", $1^{\text {a }}$ acepción.

${ }^{22}$ Cabanellas de las Cuevas, Guillermo, Régimen jurídico de los conocimientos técnicos. "Knowhow" y secretos comerciales e industriales (Buenos Aires, Heliasta, 1984), pp. 55-56.

${ }^{23}$ Dictamen de la Dirección del Trabajo, Ord N ${ }^{\circ}$ 4731/081, de 3 de noviembre de 2010. 
pueden ser objeto de este pacto serían los secretos de empresa mencionados anteriormente, vale decir: secretos técnicos industriales, secretos comerciales, y secretos sobre la organización interna de la empresa (véase el cap. II).

Siguiendo a Suñol, las principales virtudes que presentan estos acuerdos, entre otras, son las siguientes:

i) Identificar con precisión los elementos informativos que tienen la condición de secretos y sobre los que, por lo tanto, debe mantenerse la reserva;

ii) Permitir prever otros aspectos relevantes, tales como, el plazo durante el cual será exigible el deber de secreto sobre una determinada información; las consecuencias de su incumplimiento, etc.; y

iii) Establecer los medios lícitos por los que puede adquirirse el secreto, así como para complementar un acuerdo de transferencia de tecnología ${ }^{24}$.

Cabe señalar que la transmisión de conocimientos sin imponer restricciones sobre su uso, no conferirá en principio derecho a impedir dicho uso con posterioridad a la comunicación de la información ${ }^{25}$. De manera que es sobre el titular del secreto industrial o comercial en quien recae la carga de la prueba para acreditar la creación de una relación de confidencialidad ${ }^{26}$. Se manifiesta así la importancia que para dicho titular representa la existencia de un pacto de confidencialidad que dé cuenta de una obligación de reserva.

\section{Obligación de secreto del trabajador y pacto de confidencialidad.}

En nuestra opinión, la obligación del trabajador de mantener los secretos relativos a la explotación y negocios de la empresa deriva del deber de buena fe. Como apuntan Thayer y Novoa, el deber de fidelidad obliga al trabajador a no procurar "el daño para la empresa: [...] daño económico o comercial, difundiendo sus secretos industriales, técnicas de trabajo, proporcionando a otras empresas informaciones, etc." ${ }^{27}$. Así, relacionando esta materia con el artículo 1546 CC., tales consideraciones vienen a ser una manifestación del principio de la buena $\mathrm{fe}^{28}$, con el agregado que no se trataría en estos casos simplemente de "obligaciones que integran la naturaleza del negocio jurídico, sino de deberes esenciales y principales" ${ }^{29}$. En un sentido similar, Irureta

${ }^{24}$ Suñol Lucea, A., cit. (n. 3), pp. 160-161.

${ }^{25}$ Mitelman, C. - Zuccherino, D., cit. (n. 1), pp. 61-62.

${ }^{26}$ Ibíd., pp. 61-62.

${ }^{27}$ Thayer Arteaga, William - Novoa Fuenzalida, Patricio, Manual de Derecho del Trabajo (4ª edición, Santiago de Chile, Editorial Jurídica de Chile, 2007), III, p. 424.

${ }^{28}$ Sobre la aplicación del principio de la buena fe en el ámbito laboral, véase: IRUReta Uriarte, Pedro, Vigencia del principio de la buena fe en el Derecho del Trabajo chileno, en Ius et Praxis, 17 (2011) 2, pp. 133-188.

${ }^{29}$ Thayer Arteaga, W.- Novoa Fuenzalida, P., cit. (n. 27), III, p. 399. 
Uriarte considera que el respeto de este principio por parte de un trabajador "implica que éste debe abstenerse de ejecutar conductas eventualmente reprochables ('aun cuando no le hubiere especialmente prohibido')" ${ }^{30}$. En este orden de ideas, el autor recién citado indica que la buena fe envuelve la obligación del trabajador de someterse a niveles razonables de cooperación, lo que evidencia un compromiso leal con el programa negocial. Afirma así que entre los deberes de cooperación se encuentra el deber de secreto, que obliga a guardar la debida confidencialidad y discreción sobre determinados asuntos o informaciones de las cuales tome conocimiento el trabajador en razón de su cargo ${ }^{31}$. La jurisprudencia de la Corte Suprema ha manifestado un criterio similar, al fallar que "las relaciones laborales han de desenvolverse en un clima de confianza, el que se genera en la medida que las partes cumplan con sus obligaciones en la forma estipulada, fundamentalmente, de buena fe, principio del cual se encuentra imbuida toda nuestra legislación", agregando que las partes de una relación laboral tienen deberes "que si bien no han sido explicitados en el texto del contrato pertinente o consensuados expresamente, emanan de la naturaleza de la relación laboral, por ejemplo, que ninguna de las partes actuará en perjuicio o detrimento de la otra"32. Situados estos criterios específicamente en materia de confidencialidad, objeto del presente estudio, la Corte de Santiago señaló que el "deber de lealtad que tienen los trabajadores con su empleador" implica, entre otras, "la obligación de guardar el secreto de información de importancia que pertenezca al empleador"33.

Con todo, para el mantenimiento de la condición de confidencial de determinada información, es necesario que el empleador adopte ciertas precauciones que den cuenta de dicho carácter ${ }^{34}$. De lo contrario, puede producirse la pérdida de la condición secreta de cierta información, si ella llegase a conocimiento de trabajadores que no tienen relación directa con su uso, si tal circunstancia hace suponer razonablemente a esos dependientes que tales antecedentes carecen de esa naturaleza confidencial ${ }^{35}$. Por tal motivo, se sostiene que la empresa debe manifestar con claridad el deseo de mantener oculta cierta información, en orden a impedir que llegue a conocimiento de

${ }^{30}$ Irureta Uriarte, P., Vigencia, cit. (n. 28), p. 160.

${ }^{31}$ Ibíd., p. 163.

${ }^{32}$ Sentencia de la Corte Suprema, de 11 de noviembre de 2009, rol N 6611-2009. En el mismo sentido, la sentencia de la Corte Suprema, de 18 de octubre de 2012, rol $\mathrm{N}^{\circ} 821-2012$.

${ }^{33}$ Sentencia de la Corte de Apelaciones de Santiago, de 13 de enero de 1996, rol $\mathrm{N}^{\circ} 3366-1994$.

${ }^{34}$ Mitelman, C. - Zuccherino, D., cit. (n. 1), p. 10.

${ }^{35}$ Ibíd., p. 10. 
otros $^{36}$. Para esto, la empresa debe utilizar medios idóneos que constituyan la exteriorización necesaria de su voluntad de guardar el secreto.

Los medios para mantener en confidencialidad cierta información pueden ser de carácter fáctico o jurídico ${ }^{37}$. Entre los primeras, es posible destacar: $i$ ) la colocación de cerraduras en los lugares donde se almacene la información y el mantenimiento de las llaves de acceso en un lugar centralizado donde los autorizados deban requerirlas y devolverlas; $i i)$ el acceso por clave a los sistemas computacionales; iii) la delimitación de áreas restringidas, con avisos o carteles que den cuenta de tal particularidad y su acceso controlado por medio de tarjetas electrónicas; iv) la inclusión de notas o instrucciones en manuales, planos impresos y otros documentos similares, que indiquen claramente que su contenido debe ser mantenido en reserva, etc. ${ }^{38}$.

Las prevenciones destinadas a mantener la reserva de los conocimientos pueden ser no sólo de naturaleza material, sino también pueden ser de naturaleza jurídica. Ciertamente entre tales prevenciones se destacan las cláusulas de confidencialidad redactadas por el titular de la información y que obligan a los receptores de la información a conservarla oculta ${ }^{39}$. Los pactos de confidencialidad se presentan así como un instrumento sumamente necesario con miras a proteger dicha clase de conocimiento. En efecto, estos pactos constituyen la mecánica jurídica por excelencia para preservar el carácter secreto de una información ${ }^{40}$. En nuestra opinión, en gran medida, la importancia de la cláusula de confidencialidad reside en que permite especificar con claridad cuáles son las materias que la empresa considera confidenciales ${ }^{41}$.

Como apuntábamos, una de las virtudes de mayor relevancia de estos pactos consiste en determinar las materias que revisten el carácter de secretos y sobre las que, por lo tanto, debe mantenerse la reserva ${ }^{42}$. Y es que si no existe un pacto en donde se precisen las materias objeto de reserva, pueden surgir

${ }^{36}$ Grau Gabrielli, Daniela - Parker Jiménez, Jorge - Uzal Castro, José, Confidencialidad de la información reservada en la relación laboral (Santiago de Chile, tesis para optar al grado de Licenciado en Ciencias Jurídicas y Sociales, Universidad de Chile, 2007), p. 40.

${ }^{37}$ Mitelman, O - Zuccherino, D., cit. (n. 1), p. 10.

${ }^{38}$ Ibíd., pp. 19-20.

${ }^{39}$ Ibíd., pp. 21-22.

${ }^{40}$ Suñol LuCEA, A., cit. (n. 3), p. 159.

${ }^{41}$ Suñol señala que si bien la suscripción de estas cláusulas no es imperiosa cuando el sujeto que recibe o desarrolla la información confidencial se encuentra sometido a un deber legal de secreto o derivado de la buena fe -como puede ser un trabajador-, lo cierto es que hacerlo proporciona indudables ventajas y contribuye de manera significativa a evidenciar que se han establecido medidas razonables para proteger su naturaleza reservada: Suñol LuCEA, A., cit. (n. 3), p. 159.

${ }^{42}$ Mitelman, C. - Zuccherino, D., cit. (n. 1), p. 85. 
dudas en cuanto a cuáles tendrían la condición de secreto y, por ende, si son objeto de protección. Según hemos podido apreciar, nuestra legislación de propiedad industrial (Ley $\mathrm{N}^{\circ} 19.039$ ), que se refiere al secreto empresarial, lo circunscribe exclusivamente a productos y procedimientos industriales, dejando de lado otros aspectos relevantes de un negocio, como los secretos comerciales y de organización interna de la empresa. De modo que en estos casos resultará importante la existencia de una cláusula de confidencialidad que expresamente proteja tal clase de información, con miras a que no exista duda sobre su carácter secreto.

Con todo, debe advertirse que el acuerdo de confidencialidad no convierte en información secreta a aquella que es fácilmente accesible $e^{43}$. Como bien señala la Dirección del Trabajo, no parece idónea la cláusula de confidencialidad que persiga mantener reservada una información de conocimiento público ${ }^{44}$. Por consiguiente, si al momento de la suscripción del acuerdo, la información objeto del mismo y expresamente calificada en él como secreta se encontrara en el dominio público o, a pesar de haber gozado inicialmente de ese estatus hubiera perdido con posterioridad ese carácter, parece del todo razonable entender que su divulgación o explotación por quien en virtud de ese acuerdo se comprometió a mantenerla en reserva no constituye un incumplimiento contractual ${ }^{45}$.

Tampoco parecerá idónea aquella reserva que se exija respecto de la información que deriva de la experiencia adquirida al servicio de un empleador, en cuanto esté formada por conocimientos que se han integrado en la personalidad profesional del trabajador ${ }^{46}$. Por ejemplo, el ex-trabajador podrá gozar en su plenitud de la habilidad que pudo haber obtenido como jefe de ventas, su poder de convencimiento, la facilidad de vender, aun cuando haya sido específicamente entrenado para ello en su anterior empleo ${ }^{47}$.

${ }^{43}$ Suñol Lucea, A., cit. (n. 3), pp. 161-162. En el mismo sentido, Mitelman, C. - ZuCCherino, D., cit. (n. 1), p. 88.

${ }^{44}$ Dictamen de la Dirección del Trabajo, Ord N ${ }^{\circ}$ 4731/081, de 3 de noviembre de 2010.

${ }^{45}$ Suñol Lucea, A., cit. (n. 3), p. 162.

${ }^{46}$ Dictamen de la Dirección del Trabajo, Ord N ${ }^{\circ}$ 4731/081, de 3 de noviembre de 2010.

${ }^{47}$ Mitelman, C. - Zuccherino, D., cit. (n. 1), p. 88. Este criterio también ha sido sustentado en la jurisprudencia inglesa, en el caso "Faccenda Chicken Ltd v Fowler" (ICR 589, 1984), donde se señala que mientras la relación laboral exista, el trabajador deberá tratar como confidencial toda información que, una vez aprendida, necesariamente permanece en su cabeza y se vuelve parte de su propia habilidad y conocimiento. Sin embargo, cuando se ha extinguido la relación laboral, podrá usar la totalidad de su habilidad y conocimiento para su propio beneficio, aun compitiendo con su ex empleador; sobre esto, véase: Brearley, Kate - Bloch, Selwyn, Employ- 
A su vez, no deberían ampararse bajo un pacto de confidencialidad las irregularidades que suponen un funcionamiento anormal de la empresa y que, en caso de hacerse públicas, benefician el interés social ${ }^{48}$. El mismo criterio tendría que aplicarse en el caso de actos ilícitos cometidos por el empleador ${ }^{49}$.

Por otra parte, los pactos de confidencialidad no precisan de una compensación económica, sin perjuicio, claro está, de que las partes puedan pactarla si así lo estiman conveniente ${ }^{50}$. Tampoco requieren limitar sus efectos geográficamente o temporalmente, puesto que la divulgación no consentida de la información cualquiera que sea el ámbito geográfico puede perjudicar su carácter reservado y, por tanto, toda la valía del secreto empresarial ${ }^{51}$.

Por último, es necesario señalar que los acuerdos o pactos de confidencialidad sólo tienen efectos inter partes, de modo que esta protección contractual no se extenderá a terceros ajenos a esta relación. En tal sentido, en el supuesto de violación de un convenio de confidencialidad, el titular del secreto estará legitimado para iniciar acciones legales contra aquellos que no respetaron su compromiso contractual, pero carece de acción contra los terceros que accedieron a dicho secreto de buena fe; es decir, sujetos que desconocían que la revelación efectuada implicaba la infracción de un acuerdo de confidencialidad celebrado con el divulgador ${ }^{52}$. Con todo, como sostienen Mitelman y Zuccherino, si bien el tercero de buena fe será inmune ante cualquier reclamo patrimonial proveniente del legítimo poseedor de la información confidencial, deberá abstenerse de seguir sacando provecho a futuro del secreto a menos que se pacte una regalía con el poseedor de tal información ${ }^{53}$.

\section{Secreto versus libertad de trabajo.}

La Dirección del Trabajo señala que los pactos o cláusulas de confidencialidad, que emanan de los derechos constitucionales del empleador de libertad de empresa y de derecho de propiedad, pueden suponer la afectación de derechos constitucionales de los trabajadores, en particular la libertad de trabajo y la libertad de expresión ${ }^{54}$. Se señala así que se afectaría la libertad

ment Covenants and Confidential Information. Law Practice and Technique (3a edición, Tottel Publishing, Londres, 1999), p. 195.

${ }^{48}$ Véase Irureta Uriarte, P., Vigencia, cit. (n. 28), p. 163.

${ }^{49}$ Ibíd., p. 163.

${ }^{50}$ Suñol LuceA, A., cit. (n. 3), p. 161.

${ }^{51}$ Ibíd., p.161

${ }^{52}$ Mitelman, C. - Zuccherino, D., cit. (n. 1), p. 63.

${ }^{53}$ Ibíd., p. 63.

${ }^{54}$ Dictamen de la Dirección del Trabajo, Ord N ${ }^{\circ} 4731 / 081$, de 3 de noviembre de 2010. 
de trabajo en el caso que la extensión del secreto o confidencialidad pudiera limitar el desarrollo de un trabajo con posterioridad al término del contrato de trabajo ${ }^{55}$. Se sostiene asimismo que se conculcaría el derecho a la libertad de expresión, en el caso que la extensión del secreto, pudiera limitar el derecho de expresar opiniones que pudieren verse alcanzadas por la reserva exigida contractualmente, especialmente frente a un empleo posterior ${ }^{56}$.

Como una forma de resolver esta posible colisión de derechos, el organismo citado considera necesario aplicar el principio de proporcionalidad, en cuya virtud se pretende establecer una medida de valoración de toda restricción que se pretenda imponer a un derecho fundamental ${ }^{57}$. Para esto desarrolla los tres sub principios del mismo, a saber: principio de adecuación o idoneidad, principio de necesidad, y principio de proporcionalidad en sentido estricto, los que a continuación analizaremos. Cabe subrayar que estos tres sub principios se aplican de manera sucesiva y escalonada, de forma tal que sólo ha de aplicarse el sub principio de necesidad en la medida de que se superen las exigencias del sub principio de idoneidad y, del mismo modo, sólo ha de aplicarse el sub principio de proporcionalidad en sentido estricto en tanto se haya superado el sub principio de necesidad ${ }^{58}$.

a) Principio de adecuación o idoneidad. El principio de adecuación o idoneidad consiste en que el medio empleado debe resultar apto o idóneo para la consecución del fin propuesto, resultando inadecuada, en consecuencia, la limitación de un derecho fundamental cuando ella no sirva para proteger la garantía constitucional en conflicto ${ }^{59}$. Es decir, una medida restrictiva será inidónea cuando no guarde ninguna relación de causalidad con el fin propuesto ${ }^{60}$. Se deberían así rechazar las medidas del empleador que persigan un fin constitucional legítimo - protección de derechos fundamentales propios o de terceros- cuando la medida o conducta no contribuye en

${ }^{55}$ Ibíd.

${ }^{56}$ Ibíd.

${ }^{57}$ Melis Valencia, Christian, Los derechos fundamentales de los trabajadores como limites a los poderes empresariales (Santiago de Chile, AbeledoPerrot-LegalPublishing, 2009), pp. 105-106. Sobre el principio de proporcionalidad, véanse: ALEXY, Robert, Derechos fundamentales, ponderación y racionalidad, en Revista Iberoamericana de Derecho Procesal Constitucional, 11(2011), pp. 3-14, pp. 8 ss.; ARNOLD, Rainer - MARTínEz Estay, José Ignacio - ZÚÑIGa URBINA, Francisco, El principio de proporcionalidad en la jurisprudencia del Tribunal Constitucional, en Estudios Constitucionales, 10 (2012) 1, pp. 65-116.

${ }^{58}$ Melis Valencia, Chr., cit. (n. 57), p. 108.

${ }^{59}$ Dictamen de la Dirección del Trabajo, Ord N ${ }^{\circ}$ 4731/081, de 3 de noviembre de 2010.

${ }^{60}$ Melis Valencia, Christian, cit. (n. 57), p. 111. 
forma relevante al fin inmediato buscado ${ }^{61}$. De esta forma, se lleva a excluir a aquellas medidas caprichosas, arbitrarias, irracionales, inútiles y carentes de una conexión sólida con el fin que se propone ${ }^{62}$.

La Dirección del Trabajo sostiene que la obligación de confidencialidad será idónea en la medida que persiga un fin legítimo y que, razonablemente y de acuerdo a su naturaleza, pueda alcanzar dicho $\mathrm{fin}^{63}$. En este orden, se concluye que a priori parecerá idóneo el fin de cautelar cierta información que signifique una ventaja respecto de la competencia y cuya revelación, por lo mismo, implicará razonablemente un perjuicio para aquella.

Coincidimos con la Dirección del Trabajo en cuanto a que el objetivo que debe buscar la empresa al establecer este tipo de cláusulas es mantener en secreto una ventaja respecto de sus competidores, y que de ser conocida por éstos le produciría un perjuicio. Precisamente, de las disposiciones legales que se refieren al secreto de empresa es posible apreciar que el aspecto valioso que se destaca de esta clase de información consiste en que ésta proporciona a su poseedor "una mejora, avance o ventaja competitiva" (cfr. artículo 86 Ley $\mathrm{N}^{\circ} 19.039$ ), de manera que su revelación, sin duda, puede afectar "significativamente el desenvolvimiento competitivo de su titular" (inciso $8^{\circ}$ artículo 22 del Decreto-ley $\mathrm{N}^{\circ} 211$ ).

Se debe tratar entonces de una ventaja que haga a su titular más competitivo. Por competitivo se entiende: "capaz de competir, particularmente en deportes o en una actividad económica: Productos competitivos. Precios competitivos" ${ }^{64}$. Y por competir, "contender entre sí, aspirando unas y otras con empeño a una misma cosa" ${ }^{\text {"S }}$. La ventaja competitiva se traducirá, en consecuencia, en que quien la posea tendrá más posibilidades de obtener la cosa en disputa o la superioridad en algo, p. ej. una determinada posición del mercado. Así las cosas, el grado de conocimiento de una información concreta por parte de competidores (actuales o potenciales), tiene un efecto directo sobre la ventaja que su posesión otorga a su titular, ya que su desconocimiento por parte de aquéllos es, en última instancia, lo que permite situarse en una mejor posición competitiva ${ }^{66}$. Por tanto, si sus competidores

${ }^{61}$ Ugarte Cataldo, José Luis, Privacidad, trabajo y derechos fundamentales, en Estudios Constitucionales, 9 (2011) 1, , p. 28.

${ }^{62}$ González Ortega, Santiago, El conflicto entre los derechos fundamentales del trabajador y la libertad de empresa: El necesario tránsito desde el juicio de proporcionalidad al juicio de ponderación, en Revista Chilena de Derecho del Trabajo y de la Seguridad Social, 3 (2012) 6, p. 40.

${ }^{63}$ Dictamen de la Dirección del Trabajo, Ord No 4731/081, de 3 de noviembre de 2010.

${ }^{64}$ Moliner Ruiz, M., cit. (n. 19), p. 698.

${ }^{65}$ Diccionario, cit. (n. 12), s.v. "Competir", $1^{\text {a }}$ acepción.

${ }^{66}$ Suñol LuCEA, A., cit. (n. 3), p. 28. 
están en conocimiento de tal ventaja se puede perder la superioridad o posición privilegiada que se tenía, de manera que razonablemente se sufriría un perjuicio producto de dicha pérdida ${ }^{67}$. De ahí que la ventaja que su conocimiento brinda a quien la domina decrezca a medida que aumenta el número de personas que la conocen y, en su caso, la aplican ${ }^{68}$. Por tales motivos, se justifica la calificación como idóneo de un pacto de confidencialidad que persiga proteger precisamente los antecedentes que constituyen las ventajas mencionadas ${ }^{69}$.

Ahora bien, creemos que la justificación de una cláusula de confidencialidad no se basará siempre en la protección de una ventaja competitiva. Como vimos, puede fundamentarse en el cumplimiento de un imperativo legal, como sucede con la información reservada referida a sociedades calificadas y cuentas bancarias.

A su vez, su justificación se puede encontrar en la protección del derecho fundamental consistente en el respeto y protección de la vida privada de la persona del empleador y su familia ${ }^{70}$. Como se sabe, por empleador se entiende a "la persona natural o jurídica que utiliza los servicios intelectuales o materiales de una o más personas en virtud de un contrato de trabajo" (cfr. artículo $3^{\circ}$ letra a)CT). Según se aprecia, se trata de una definición bastante amplia, de modo que puede ser empleador no exclusivamente quien sea titular de una empresa, como p. ej. sería el caso de la persona natural o la familia que contrata los servicios de un trabajador de casa particular (cfr. artículo 146 CT). En este contexto, el contenido de la cláusula puede referirse a cuestiones propias de la vida privada de una persona y su familia, cuando dada la naturaleza de los servicios prestados - p. ej. un trabajador de casa particular - se tiene contacto con esa clase de información en forma habitual. A este respecto, se presenta ilustrativa la Ley $\mathrm{N}^{\circ} 19.628$ sobre Protección de la vida privada, que considera antecedentes "sensibles" a aquellos que "se refieren a las características físicas o morales de las personas o a hechos $o$ circunstancias de su vida privada e intimidad, tales como los hábitos personales, el origen racial, las ideologías y opiniones politicas, las creencias o convicciones religiosas, los estados de salud físicos opsíquicos y la vida sexual" [letra g) artículo

${ }^{67}$ Ibíd.

${ }^{68}$ Ibíd.

${ }^{69} \mathrm{La}$ Corte de Santiago califica con incumplimiento grave la infracción de una cláusula de un contrato de trabajo que reconoce el carácter de confidencial a "listados de clientes, listados de programas, técnicas de administración y programación”; véase la sentencia de la Corte de Santiago, 17 de julio de 2009, rol No 1780-2008.

${ }^{70}$ Irureta Uriarte, P., Vigencia, cit. (n. 28), p. 163. En la jurisprudencia, véase la Sentencia del Primer Juzgado de Letras de Santiago, de 19 abril de 2012, RIT N ${ }^{\circ} \mathrm{O}$ 3997-2011. 
2 de la Ley $N^{\circ}$ 19.628]; todos los cuales, según la Corte de Santiago, forman parte del patrimonio moral de las personas y del campo de sus afectos, cuya publicidad, utilización o entrega sin su autorización, violando su intimidad, pueda causar grave desdoro o perjuicio moral ${ }^{71}$.

b) El principio de necesidad. La Dirección del Trabajo entiende que la cláusula de confidencialidad será necesaria en la medida que para cautelar el bien jurídico protegido no exista un medio menos gravoso para el ejercicio de los derechos constitucionales de los trabajadores afectados ${ }^{72}$. Este juicio parcial de proporcionalidad ha sido también denominado como "principio de indispensabilidad", en el sentido de evaluar si la medida es indispensable para el logro de un fin empresarial ${ }^{73}$. Se exige así que la medida restrictiva de un derecho fundamental sea la única que puede alcanzar la finalidad perseguida o que, existiendo medios alternativos igualmente eficaces, sea la menos gravosa para el derecho que se pretende limitar ${ }^{74}$.

En este orden, la Dirección del Trabajo considera que la necesidad de la cláusula de confidencialidad tendría que sustentase en el hecho que para la empresa, con miras al cumplimiento de sus objetivos, debe resultar indispensable comunicar cierta información reservada a algunos de sus trabajadores. Pues de no ser así, el camino más razonable consistiría en guardar silencio respecto de tal información, con lo cual se evitaría afectar el ejercicio de derechos constitucionales de los trabajadores ${ }^{75}$.

Sobre este punto, cabe señalar -siguiendo Mitelman y Zuccherino- que resulta sumamente difícil exigir que sólo el titular tenga acceso a los conocimientos secretos, pues ello imposibilitaría en la mayoría de los casos la utilización y provecho económico de esos datos, los cuales requieren para ello de su comunicación a trabajadores u otros círculos limitados de personas ${ }^{76}$. En efecto, el empleo económicamente útil de tecnología requiere generalmente su conocimiento (en distinto niveles) por un conjunto de individuos que, actuando en el ámbito de una estructura empresarial, tienen acceso a la información que la compañía titular decide mantener en secreto ${ }^{77}$.

No hay duda de que existen una serie de antecedentes que forman parte

${ }^{71}$ Sentencia de la Corte de Santiago, de 9 de noviembre de 2011, rol No 153-2011.

${ }^{72}$ Dictamen de la Dirección del Trabajo, Ord No 4731/081, de 3 de noviembre de 2010.

${ }^{73}$ Ugarte Cataldo, J. L., Privacidad, cit. (n. 61), p. 29.

${ }^{74}$ Melis Valencia, Chr., cit. (n. 57), p. 112.

${ }^{75}$ Dictamen Dirección del Trabajo, Ord N ${ }^{\circ}$ 4731/081, de 3 de noviembre de 2010.

${ }^{76}$ Mitelman, C. - Zuccherino, D., cit. (n. 1), p. 9. En el mismo sentido, CaBanellas de las Cuevas, Guillermo, Régimen jurídico de los conocimientos técnicos. "Knowhow" y secretos comerciales e industriales (Buenos Aires, Heliasta, 1984), p. 55.

${ }^{77}$ Mitelman, C. - Zuccherino, D., cit. (n. 1), p. 9. 
del secreto de empresa, entendido en un sentido amplio (véase cap. II). Prueba de esto son las normas legales antes indicadas, donde se detallan distintos aspectos del quehacer de ciertas entidades que merecen mantenerse en secreto. Como consecuencia de lo anterior, quienes se hayan familiarizado con tales antecedentes en el desempeño de sus funciones, como sucederá con determinados trabajadores dependientes, tendrán que cumplir con dicha obligación de reserva.

Recordemosque en una organización empresarial existe lo que se denomina jerarquía, donde el poder directivo del empleador suele ejercerse de modo escalonado $^{78}$, y por medio de distintos trabajadores que tienen a su cargo diferentes secciones o etapas de la producción, los que van a dar instrucciones a aquellos dependientes que se encuentran bajo su ámbito de acción ${ }^{79}$.En este contexto, para los primeros cargos en la escala jerárquica será usual estar en conocimiento de aspectos reservados de la empresa, a partir de los cuales se transmitirá esta información hacia los niveles inferiores que corresponda con miras a lograr los objetivos propios de la organización.

Hasta qué punto se requerirá transmitir esa información, será una cuestión que dependerá de cada empresa en particular. Pero, claro está, que la existencia de un pacto de confidencialidad dará cuenta, en principio, de la necesidad, por una parte, de revelar información a un trabajador para que pueda cumplir sus funciones, y, por otra, que las partes entienden el carácter reservado de aquélla.Por lo tanto, en virtud de dicho pacto el empleador estará, en principio, en condiciones de exigir al trabajador respectivo que respete la confidencialidad estipulada.

Como decíamos, el cargo o nivel de trabajadores que estarán en conocimiento de cuestiones reservadas dependerá de cada empresa. Para esto, la "necesidad" de la confidencialidad estará dada por el puesto de trabajo y el tipo de información. Así, los cargos de mayor jerarquía, los que podrían ser calificados de exclusiva confianza ${ }^{80}$, seguramente estarán en conocimiento de

${ }^{78}$ De Val Tena, Ángel, Los trabajadores directivos de la empresa (Navarra, Arazandi, 1999), p. 41.

${ }^{79}$ Véase: Vázeuez Vialard, Antonio, Derecho del Trabajo y de la Seguridad Social (Buenos Aires, Astrea, 1996), pp. 287-288.

${ }^{80}$ Tratándose de los trabajadores resulta habitual que la mayor confianza se vincule con la responsabilidad del cargo. Se afirma así que "el factor confianza va tomando definición en la medida en que aumenta la responsabilidad por la labor a realizar”. Siendo un elemento determinante en tal sentido el que un cargo y las "funciones de importancia" que conlleva, requieran en el más alto "grado de creencia" por parte del empleador; como la "dirección de un proyecto", o tareas de índole "comercial", "control técnico", manejo de "información reservada", etc. Se trataría de cargos que realizan tareas que comportan cierta dirección en un área especializada o determinada, que resultan claves para la empresa; de ahí que requieran la confianza más elevada por parte del empleador, 
antecedentes relativos a "políticas futuras de inversiones de la empresa" (cfr. el inciso $5^{\circ}$ del artículo $315 \mathrm{CT}$.), como también otro tipo de información que se conciba como confidencial.

Sobre el punto, resulta ilustrativo el ordenamiento laboral peruano, ya que define como trabajadores de confianza a "aquellos que laboran en contacto personal y directo con el empleador o con el personal de dirección, teniendo acceso a secretos industriales, comerciales o profesionales y, en general, a información de carácter reservado" (cfr. el artículo 43 del Decreto-ley $\mathrm{N}^{\circ}$ 728).En esta línea, nuestra jurisprudencia afirma que "la exclusiva confianza recorre desde las funciones que cumple un trabajador [...] hasta aquellas en las que el trabajador debe guardar secretos para mantener determinado contacto con la vida íntima del empleador o porque se relacionan con trabajos personales del empleador dentro de la empresa o establecimiento, como es el caso del tesorero, pagador, etc." ${ }^{\text {. }}$.

Por su parte, el secreto de empresa, a que alude la Ley $\mathrm{N}^{\circ} 19.039$, adquiere especial importancia como medio de protección anterior a una patente de invención $^{82}$. Y es que precisamente si no se respeta dicho secreto, se puede poner en peligro el carácter de "nueva" de una invención, que se exige para que ella sea patentable (cfr. El artículo 32 de la Ley $\left.\mathrm{N}^{\circ} 19.039\right)^{83}$. En este caso, la importancia de mantener la reserva se extenderá a todos los trabajadores que estén trabajando en el desarrollo de la posible invención, más allá de su grado jerárquico.

A su vez, en el caso de los trabajadores que trabajen en un Banco les asistirá, sin importar su cargo, el deber de secreto bancario, en el caso que les corresponda tratar, en el ejercicio de sus funciones, con cuestiones propias de este secreto (cfr. el artículo 154 Ley general de bancos).

c) Principio de proporcionalidad. El principio de proporcionalidad en sentido estricto consiste en la ponderación de intereses en conflicto, para

de manera que su función no puede "encomendarse a cualquier persona, sino en quien se hace fe de su comportamiento y moralidad"; véase Sierra Herrero, Alfredo, $A s$ pectos laborales del gerente: representación empresarial y desabucio, en Revista de Derecho de la Empresa, 20 (2009), pp. 36-37.

${ }^{81}$ Sentencia del primer Juzgado de Letras de Santiago, de 19 abril de 2012, RIT N ${ }^{\circ}$ O 3997-2011.

${ }^{82}$ Lois Bastida, Fátima, La protección del inventor asalariado (Madrid, Civitas, 2000), p. 243.

${ }^{83}$ De acuerdo al artículo 33 de la Ley $\mathrm{N}^{\circ} 19.039$, se entiende que una invención es nueva "cuando no existe con anterioridad en el estado de la técnica. El estado de la técnica comprenderá todo lo que haya sido divulgado o hecho accesible al público, en cualquier lugar del mundo, mediante una publicación en forma tangible, la venta o comercialización, el uso o cualquier otro medio, antes de la fech a de presentación de la solicitud de patente en Chile o de la prioridad reclamada, según el artículo 34". 
determinar el que debe ser prioritario en el caso concreto ${ }^{84}$. Se trata de una ponderación que consiste en constatar si la medida restrictiva del derecho fundamental de un trabajador es equilibrada, por derivarse de ella más ventajas y beneficios para el interés empresarial a proteger, que perjuicios sobre el derecho fundamental afectado ${ }^{85}$. En este sentido, la Dirección del Trabajo sostiene que la imposición de la confidencialidad será proporcional si resulta en el caso concreto en que se aplique, de mayor importancia cautelar el derecho del empleador materializado en la obligación de secreto, que los derechos constitucionales de los trabajadores que podrían verse afectados ${ }^{86}$.

El aspecto valioso del secreto empresarial consiste en que su titular posee una ventaja en relación a un competidor. De esta suerte, si la cláusula se ciñe expresamente a aquellos aspectos relativos a dicha ventaja competitiva, su establecimiento sería proporcionalmente justificado frente a los derechos de la libertad de trabajo y la libertad de expresión del trabajador. Si la cláusula de confidencialidad cumple con los términos indicados, los derechos de la libertad de trabajo y la libertad de expresión del trabajador no serían afectados, o bien lo serían levemente ${ }^{87}$.

Por el contrario, si en una cláusula de confidencialidad se incluyen cuestiones que son de conocimiento público o materias que constituyen ideas que se han integrado en la personalidad profesional del trabajador ${ }^{88}$,ésta carecería de la justificación necesaria, toda vez que se estaría dando el carácter de confidenciales a aspectos que en realidad no lo son. En este escenario, el derecho a la libertad de trabajo estaría limitado seriamente. $Y$ es que la empleabilidad del trabajador con posterioridad al término del contrato de trabajo -que contiene la cláusula de confidencialidad- se vería lesionada al no poder desarrollar p. ej. los conocimientos-que no siendo secretos de empresa-se adquieren normalmente como consecuencia del ejercicio práctico de una profesión u oficio. En efecto, el derecho del empleador a guardar reserva de sus antecedentes no se vulneraría, pues en este supuesto, éstos no presentarían el carácter de secretos. En cambio, el derecho a la libertad de trabajo del trabajador se vería afectado gravemente. De este modo, en el juicio de proporcionalidad debería primar este segundo derecho por sobre el primero ${ }^{89}$, ya que cuanto mayor sea el grado de no cumplimiento o de no

\footnotetext{
${ }^{84}$ GonZález Ortega, S., cit. (n. 62), p. 45.

${ }^{85}$ Ibíd.

${ }^{86}$ Dictamen de la Dirección del Trabajo, Ord N 4731/081, de 3 de noviembre de

${ }^{87}$ Véase la nota 89.

${ }^{88}$ Dictamen de la Dirección del Trabajo, Ord N ${ }^{\circ}$ 4731/081, de 3 de noviembre de
} 2010. 2010.

${ }^{89}$ Ugarte Cataldo, J. L., Privacidad, cit. (n. 61), pp. 31-32 -siguiendo a Ale- 
satisfacción de un derecho fundamental, tanto mayor debe ser la importancia del cumplimiento del otro ${ }^{90}$.

Con todo, como veíamos, existen antecedentes cuyo carácter de reservado deviene de un mandato legal. En estos supuestos, dado que la confidencialidad de la información constituye una exigencia legal, las cláusulas de confidencialidad que se refieran a dichas cuestiones se presentan como proporcionales desde que protegen no sólo intereses del empleador, sino también de terceros, tales como, aspectos íntimos de una persona (Ley de protección de la vida privada), cuentas bancarias (Ley general de bancos), e información de sociedades clasificadas (Ley de mercado de Valores). Por consiguiente, en estos casos presenta mayor importancia cautelar la información reservada, que la posibilidad del trabajador de revelar dicha información.

\section{Plazo de duRación de los pactos de Confidencialidad}

En la práctica, el plazo de duración de una cláusula de confidencialidad puede variar en cada caso. Teniendo como referencia el contrato de trabajo, la duración de los pactos de confidencialidad suele derivar en los siguientes supuestos: $i$ ) por todo el período de vigencia del contrato de trabajo; ii) por todo el período de vigencia del contrato de trabajo y un lapso posterior determinado en el tiempo; $y$ iii) por todo el período de vigencia del contrato de trabajo y un lapso posterior de carácter indefinido.

No existe duda que bajo la vigencia el contrato de trabajo, la cláusula de confidencialidad se podrá pactar por toda la duración de éste. En ese período el empleador facilita al trabajador todos los medios necesarios para el correcto cumplimiento de su prestación, pero al mismo tiempo bajo ese esquema reside el riesgo empresarial de que aquellos intereses competitivos (clientela, proveedores, informaciones, etc.) le sean arrebatados y comunicados a terceros competidores ${ }^{91}$.

Creemos que una vez terminado el contrato dicho riesgo empresarial se mantiene, pues el ex trabajador puede haber estado en contacto con información o antecedentes confidenciales que puede difundir después de terminada

$\mathrm{XY}$ - señala que para permitir la comparación entre los derechos en colisión, se propone una escala con tres niveles de intensidad de afectación de derecho fundamental: grave, media o leve. Continúa dicho autor indicando que en el juicio de proporcionalidad en sentido estricto el derecho más importante, de acuerdo al juicio de valor de intensidad efectuado, desplaza al derecho menos importante para ese caso en concreto.

${ }^{90}$ Véase: Ugarte Cataldo, José Luis, Derecho, trabajo y privacidad (Santiago de Chile, AbeledoPerrot-LegalPublishing, 2011), p. 106.

${ }^{91}$ Nogueira Guastavino, Magdalena, Pacto laboral de no competencia postcontractual (Madrid, McGraw-Hill, 1998), pp. 47-48. 
la relación laboral. Es más, se podría pensar que existe mayor peligro en que se divulgue tal clase de información cuando el contrato de trabajo ha finalizado, toda vez que el trabajador deja de estar vinculado con la empresa de modo que el grado de compromiso para con ésta se ha debilitado. En tal sentido, Alonso Olea y Casas Baamonde afirman que los secretos relativos a la explotación y negocios deben perdurar tras la extinción del contrato de trabajo ${ }^{92}$.

Surge la pregunta de si es válido pactar este tipo de cláusula con carácter indefinido, una vez finalizado el contrato de trabajo. A nuestro entender el aspecto clave reside en determinar hasta qué punto la divulgación de la información confidencial puede causar perjuicio a su titular. Nos parece así razonable que una cláusula de confidencialidad -si se ha pactado de manera indefinida- puede obligar a un ex trabajador por todo el período en que su revelación provoque dicho perjuicio. Así, p. ej., si la cláusula de confidencialidad es concerniente a políticas de inversiones futuras de la empresa ${ }^{93}$, el deber de reserva debería mantenerse por todo el período en que no se hayan realizado dichas inversiones, pero una vez que éstas se han materializado, sería una cuestión de conocimiento público.

No es de extrañar la existencia cláusulas de confidencialidad de carácter indefinido en los términos antes mencionados. Así, en materia de información privilegiada -de acuerdo a los artículos 164 ss. de la Ley $\mathrm{N}^{\circ} 18.045$ - se dispone expresamente que las personas que estén obligadas a guardar reserva, mantienen dicha obligación aun cuando haya cesado las relación con los ligaba con la entidad emisora de valores, sin que se establezca un plazo límite a este respecto (cfr. el artículo 167 de la Ley $\mathrm{N}^{\circ} 18.045$ ). Otro tanto sucede en materia de secreto profesional, donde existen disposiciones que establecen que el deber de reserva no se extingue por el término de la relación profesional, la muerte del cliente, ni el transcurso del tiempo (artículo 47 Código de Ética Colegio de Abogados).

Para finalizar, creemos que resume muy bien lo que hemos expuesto, una sentencia de la Cámara Comercial argentina, según la cual, "el deber de reserva o secreto sobre ciertas informaciones importantes, procedimientos u otros hechos vinculados con la empresa, de los cuales el trabajador hubiera tomado conocimiento en razón de la relación laboral y cuya injustificada divulgación podría causar daño concreto a la empresa por su valor comercial,

\footnotetext{
${ }^{92}$ Alonso Olea, Manuel - Casas BaAmonde, María Emilia, Derecho del Trabajo (24a edición, Madrid, Civitas, 2006), p. 370.

${ }^{93} \mathrm{El}$ inciso $5^{\circ} \mathrm{del}$ artículo $315 \mathrm{CT}$. relativo a la negociación colectiva, dispone que el empleador entregará a la comisión negociadora de los trabajadores "la información pertinente que incida en la politica futura de inversiones de la empresa, siempre que no sea considerada por aquél como confidencial".
} 
existe mientras dura el contrato de trabajo y persiste después de su extinción en tanto subsistan los fines de protección del empleador legitiman el deber" ${ }^{\text {"4́ }}$.

\section{NATURALEZA JURÍdica Y COMPETENCIA JUDICIAL}

De acuerdo al artículo $10 \mathrm{CT}$, el contrato de trabajo debe contener obligatoriamente una serie de estipulaciones, tales como la individualización de las partes, la determinación de la naturaleza de los servicios, el monto, forma y período de pago de la remuneración acordada, la duración y distribución de la jornada de trabajo, etc. Asimismo, esta disposición prescribe que las partes podrán acordar en el contrato otros "pactos". Evidentemente, dentro de esta clase de pactos se podría encontrar una cláusula de confidencialidad, ya sea acordada a partir de la suscripción del contrato, o bien, con posterioridad a través de un anexo.

Según se puede apreciar, esta cláusula tiene su fundamento en el marco de un contrato de trabajo. En efecto, el contrato es la causa para que la empresa le transmita al trabajador información confidencial que sea requerida para prestar sus servicios, y de ahí que surja la necesidad para la empresa de estipular un deber de reserva. Por tales motivos, consideramos que este tipo de estipulación tiene naturaleza laboral. Tal criterio lo mantenemos aun cuando se trate de cláusulas que se suscriban para regir no sólo durante la vigencia del contrato de trabajo, sino también con posterioridad al cese de éste, toda vez que el fundamento en ambos supuestos es el mismo: la relación laboral que liga o ligó a las partes, según decíamos.

El considerar como "laborales" esta clase de pactos tiene importancia para efectos de determinar la competencia de los tribunales que estarían llamados a conocer las cuestiones que susciten su cumplimiento. Vigente la relación laboral creemos que no existe duda en cuanto a entender que el tribunal competente es el juez del trabajo, puesto que éste se encuentra facultado para resolver sobre "las cuestiones suscitadas entre empleadores y trabajadores por aplicación de las normas laborales o derivadas de la interpretación y aplicación de los contratos individuales o colectivos del trabajo o de las convenciones [...]" [letra a) del artículo 420 CT.].

Las dudas las ofrece el conocimiento de una cláusula de confidencialidad que pueda operar con posterioridad a la vigencia del contrato. Antes de entrar al fondo del asunto, cabe apuntar que no merece reparos el que una cláusula del contrato subsista una vez cesado éste. No es novedad que una vez

${ }^{94}$ Cámara Nacional de Apelaciones en lo Comercial, sala A, 24 de marzo de 2000, cit. en Grisolía, Julio Armando - Hierrezuelo, Ricardo Diego, Derechos y deberes en el contrato de trabajo (Buenos Aires, AbeledoPerrot, 2010), p. 499. 
expirado un contrato, cualquiera que sea, se puedan mantener subsistentes obligaciones entre las partes, aun cuando no estén expresamente estipuladas. Sobre la base de la regla de la buena fe objetiva, López Santa María sostiene que la idea de dichas obligaciones es impedir conductas mediante las cuales una parte pudiere disminuir las ventajas patrimoniales legítimas de la otra ${ }^{95}$. Ciertamente, destaca entre las conductas que impone la buena fe después de la finalización del contrato, la de secreto o reserva. El autor citado-siguiendo a Mosset Iturraspe- señala que “es éste el más evidente de todos los deberes. Aquellas cuestiones que uno de los contratantes hubiere conocido con motivo o en ocasión del contrato celebrado y ejecutado y cuya difusión o conocimiento por terceros puedan dañar a la contraparte deben permanecer en el secreto o reserva" 96 . Añade López Santa María que la obligación de secreto no sólo concierne a los contratos terminados de licencia, de know-how, $\mathrm{u}$ otros relacionados con la propiedad industrial (patentada o no), sino que muy particularmente a los contratos de servicios profesionales, por ejemplo, al secreto profesional que liga de por vida al abogado con su ex cliente ${ }^{97}$.

Volviendo al tema de la competencia, surge la pregunta sobre si el juez del trabajo podría conocer esta clase de asuntos, toda vez que la relación laboral ha finalizado, y, por tanto, sería una materia que cabe dentro de la órbita de la justicia ordinaria.

A este respecto, es importante tener en cuenta que la Corte de Santiago, pronunciándose sobre cuál es el tribunal -civil o laboral- que debe conocer de un incumplimiento de una cláusula de no competencia post-contractual ${ }^{98}$-es decir, una cláusula que debe operar con posterioridad al término del contrato de trabajo- resuelve que el juez del trabajo es competente. Sostiene así que "las exigencias naturales de ciertos asuntos aconsejan las especialización de la función jurisdiccional, generándose así la competencia de los tribunales especiales, como ocurre con los laborales, que están llamados por la ley a pronunciarse, entre otros, sobre los conflictos individuales derivados de las relaciones emanadas del contrato de trabajo, cuyo carácter técnico y social exige un conocimiento especializado" 99 . En definitiva, concluye que "la obligación que se invoca como fuente de la responsabilidad reclamada corresponde a una surgida a raiz de la relación laboral que vinculara a las partes, cuya definición y alcance, por consiguiente, tiene relación con materias propias del Derecho del Trabajo"100.

${ }^{95}$ López Santa María, Jorge, Los contratos. Parte general (5a edición, Santiago de Chile, AbeledoPerrot-LegalPublishing, 2010), p. 359.

${ }^{96}$ Ibíd., p. 360.

${ }^{97}$ Ibíd.

${ }^{98}$ Sentencia de la Corte de Santiago, 13 de mayo de 2008, rol № 5263-2007.

${ }^{99}$ Ibíd.

${ }^{100}$ Ibíd. 
La Corte Suprema, conociendo de un recurso de casación en el fondo en contra de la sentencia antes citada, confirma el criterio de la Corte de Santiago. En este sentido, se afirma que es "requisito indispensable para atribuir la competencia a los jueces laborales [...] que la controversia o materia a resolver diga relación con los conflictos que se suscitan por la aplicación $y / o$ interpretación de las normas laborales $y / 0$ de los contratos de trabajo entre personas que están o han estado ligadas por una relación laboral" ${ }^{101}$. Nótese que la Corte Suprema considera que un juez del trabajo es competente para conocer aquellas cuestiones concernientes a un contrato de trabajo "entre personas que están o han estado ligadas por una relación laboral".

Coincidimos con la Corte en cuanto a que el aspecto clave para determinar la competencia laboral emana de la aplicación de un contrato de trabajo, entre las partes que estuvieron ligados por él, más allá de si éste siguió rigiendo o no en su totalidad ${ }^{102}$. Como sabemos, a pesar de su término es posible que hayan quedado obligaciones pendientes de cumplimiento, como sucede como una cláusula de no competencia post-contractual o un pacto de confidencialidad. En este contexto, la causa de la existencia de este tipo de cláusulas es la relación laboral. Si ésta no hubiere existido, el trabajador no habría accedido a información confidencial de la empresa y, por tanto, no surgiría la necesidad de tal clase de estipulaciones.

El que se reconozca a la relación laboral como causa o fundamento de este tipo de cláusulas resulta importante a la hora de justificar su validez. Recordemos que a través de ellas se puede afectar, en mayor o menor medida, derechos fundamentales, tales como la libertad de trabajo y la libertad de expresión. Según veíamos, la justificación para tal limitación se encontraba en el interés legítimo del empleador de proteger información confidencial que p. ej. que ella en manos de un competidor le podría producir un perjuicio. Dicha información confidencial se había puesto en conocimiento del trabajador precisamente para cumpliera con la prestación debida emanada del contrato de trabajo. Por tal motivo, aun cuando la cláusula puede operar

${ }^{101}$ Sentencia de la Corte Suprema, de 30 de septiembre de 2008, rol N ${ }^{\circ}$ 4301-2008.

${ }^{102}$ En este caso, el fundamento legal de la competencia se encontraría en el artículo 420 letra a) CT., a cuyo tenor corresponde a los jueces de letras del trabajo conocer de las cuestiones suscitadas entre empleadores y trabajadores por aplicación de las normas laborales o derivadas de la interpretación y aplicación de los contratos individuales o colectivos del trabajo o de las convenciones y fallos arbitrales en materia laboral. Creemos que aun cuando la norma se refiere a empleadores y trabajadores, no se debe restringir su interpretación únicamente a aquellos casos en que se mantenga una relación laboral vigente. Lo crucial es que se trate de cuestiones derivadas de la interpretación y aplicación de contratos individuales o colectivos del trabajo, a pesar que éstos hayan llegado a su término; lo que, por lo demás, sucede cuando los tribunales resuelven sobre la procedencia de un despido. 
con posterioridad al término de contrato, no pareciera acertado desligar a aquélla de éste, pues la primera tiene el fundamento de su validez en la relación laboral.

\section{INFRACCIÓN DEL DEBER DE RESERVA}

\section{Incumplimiento de la cláusula de confidencialidad.}

El pacto de confidencialidad implica para el trabajador una obligación de no hacer, consistente en la abstención de divulgar información que se entiende reservada. De este modo, este pacto se infringirá cuando el trabajador obligado a guardar reserva transmite la información objeto del secreto.

Dicha revelación se puede producir, tanto durante la vigencia del contrato de trabajo, como una vez que éste se ha extinguido. Por tal motivo, es usual que las cláusulas de confidencialidad establezcan la obligación de guardar reserva aun cuando la relación laboral haya finalizado. Y es que la información confidencial no pierde ese carácter por dicho cese contractual, de manera que su divulgación igualmente puede provocar un perjuicio a la empresa, que es su titular.

El incumplimiento de este tipo de cláusula se puede reconducir por la empresa a través de dos vías: la primera, es el despido del trabajador, y la segunda, la indemnización por daños y perjuicios. Si la relación laboral se encuentra vigente, la empresa podrá optar por una de estas opciones -que normalmente será el despido- o por ambas conjuntamente. En cambio si el contrato de trabajo ha finalizado, la vía que le quedará a la empresa será la indemnización de daños y perjuicios.

\section{El despido del trabajador incumplidor.}

Si vigente la relación laboral se infringe una cláusula de confidencialidad, evidentemente estaremos en presencia de un incumplimiento del contrato de trabajo.En principio, si se produce este incumplimiento, la ejecución forzada importará lograr el cese de la actividad prohibida. No obstante, esta ejecución resultará de difícil materialización, pues normalmente una vez divulgada todo o parte de la información secreta, ésta perdería dicho carácter con lo cual ya no sería posibleel cumplimiento íntegro de la cláusula o pacto(véase el cap. VI,3).

Por consiguiente, una de las vías que tendrá la empresa para enfrentar este incumplimiento será el de proceder al despido del trabajador. Tal despido podrá estar fundado en la causal de falta de probidad (cfr. la letra a) $\mathrm{N}^{\circ} 1$ del artículo $160 \mathrm{CT}$.) o del incumplimiento grave de obligaciones contractuales (cfr. núm. 7 del artículo 160 CT.), toda vez que la divulgación de información confidencial implica que el contrato "no se está realizando de buena fe o el 
contratante respectivo no está siendo diligente al desarrollar las funciones para las que se le contrató" 103 . En efecto, la revelación de antecedentes reservados de la empresa nos parece que reviste la gravedad necesaria para configurar las causales antes mencionadas -en particular la falta de probidad, según veremos-, sobre todo en caso de existencia de una cláusula de confidencialidad que detalle los antecedentes que merecen la reserva por parte del trabajador ${ }^{104}$.

Tal conclusión es posible deducirla de una serie de normas legales, entre las que destacamos el artículo 290 letra e) CT. y el artículo 284 CPen. El artículo 290 letra e) CT. Califica como una práctica desleal en la negociación colectiva la actuación de "los miembros del directorio de la organización sindical" consistente en divulgar a "terceros ajenos a éste los documentos o la información que hayan recibido del empleador y que tengan el carácter de confidencial o reservado". Como se advierte, la sola divulgación de antecedentes confidenciales o reservados configura la acción "desleal”, es decir, la divulgación per se implica incurrir en la infracción. No se exige entonces que los directores sindicales con dicha revelación tengan un ánimo, bien de perseguir un beneficio propio o de terceros, bien de perjudicar a la empresa.

De esta norma, es posible concluir que para el legislador la revelación de información confidencial se estima como una actuación desleal. En tal sentido, creemos que la consideración de deslealtad en general - no circunscrita a la negociación colectiva - también operaría en caso que la revelación de esa información se efectúa por cualquier trabajador, sobre todo si tiene suscrita una cláusula de confidencialidad. Si concluimos que dicha revelación implica una actuación desleal, resulta que claramente estaríamos en presencia de una actuación que no está permitida en el marco de una relación laboral, ya que ambos contratantes deben cumplir "fiel y honestamente aquello que le corresponde por el contrato" ${ }^{105}$. Esto conlleva un comportamiento recíproco leal en el cumplimiento de los derechos y de las obligaciones correspondientes ${ }^{106}$.

${ }^{103}$ Sentencia de la Corte Suprema, de 29 de julio 2009, rol N $3038-2009$.

${ }^{104} \mathrm{La}$ doctrina argentina entiende que el incumplimiento del deber de guarda y secreto por parte de un trabajador es constitutivo de justa causa de despido, por constituir una injuria grave que no permite la consecución de la relación laboral (cfr. artículo 242 de la Ley N 20.744 [argentina], de Contrato de Trabajo); véase Grisolía, J. A. - Hierrezuelo, R. D., cit. (n. 94), p. 499. En el mismo sentido, Mitelman, C. ZuCCherino, D., cit. (n. 1), p. 83.

${ }^{105}$ Martín Valverde, Antonio - Rodríguez-Sañudo Gutiérrez, Fermín García Murcia, Joaquín, Derecho del Trabajo (15ª edición, Madrid, Tecnos, 2006), p. 568.

${ }^{106}$ Ibíd., p. 568. 
De ahí que el trabajador debe abstenerse de todo lo que suponga deslealtad o abuso de confianza en las gestiones confiadas ${ }^{107}$.

Es por ello que si bien parte de la jurisprudencia ha entendido que estas infracciones se incardinan en la causal de despido de incumplimiento grave de obligaciones contractuales (cfr. núm. 7 artículo $160 \mathrm{CT}$ ) ${ }^{108}$, nos parece más certero que ellas sean constitutivas de la causal de falta de probidad (cfr. a núm. 1 artículo $160 \mathrm{CT})^{109}$. En efecto, como afirman Thayer y Novoa, "la deslealtad es una típica muestra de esta causal"110, citando en apoyo de esta tesis una sentencia donde se concluye que incurre en falta de probidad "la trabajadora que proporciona a empresa de la competencia información confidencial, consistente en proporcionar vía fax a otra ISAPRE, los listados sobre tarifados y término de vigencias de los contratos, a los que tenía acceso en su calidad de secretaria administrativa"111.

Creemos que la divulgación en sí de información confidencial supone una falta de lealtad, sin importar si se ha causado un daño a la empresa que es su titular. Esto se debe a que, como señala Munita, el examen para determinar la gravedad del incumplimiento debería centrarse fundamentalmente en la conducta infractora y no en el daño que ésta pueda provocar ${ }^{112}$, y es que éste es sólo una manifestación o consecuencia del incumplimiento y no una causa del mismo ${ }^{113}$. Como se sabe, el trabajador tiene la obligación de guardar fidelidad a su empleador para no defraudar la confianza depositada a su respecto ${ }^{114}$. De ello se sigue que al infringirse este deber no es la cuantía

${ }^{107}$ Diéguez Cuervo, Gonzalo, Lecciones de Derecho del Trabajo ( $4^{a}$ edición, Madrid, Marcial Pons, 1995), p. 25

${ }^{108}$ Véase, en este sentido, la sentencia de la Corte de Santiago, de 17 de julio de 2009, rol N 1780-2008 y la de la Corte de Chillán, de 3 de abril de 2009, rol N ${ }^{\circ} 12$ 2009.

${ }^{109}$ Como señala Irureta Uriarte, Pedro, La falta de probidad como causa de extinción del contrato de trabajo, en Pereira, R. - CaAmaño, E. (coordinadores), Estudios de Derecho del Trabajo y de la Seguridad Social. Doctrina chilena y extranjera (Santiago de Chile, AbeledoPerrot - LegalPublishing, 2012), II, p. 365, la falta de probidad "se alzó como una expresión lo suficientemente apta como para configurar un comportamiento fraudulento, abusivo o carente de rectitud dentro del contrato de trabajo";

${ }^{110}$ Thayer Arteaga, William - Novoa Fuenzalida, P., cit. (n. 27), IV, p. 48.

${ }^{111}$ Sentencia del Sexto Juzgado de letras del Trabajo, de marzo de 1996, confirmada por la Corte de Apelaciones de Santiago en sentencia de 26 de junio de 1996. cit. Por Thayer Arteaga, W. - Novoa Fuenzalida, P., cit. (n. 27), IV, p. 49.

${ }^{112}$ Munita Luco, Enrique, El perjuicio económico como elemento de configuración de la gravedad del despido (Santiago de Chile, tesis para optar al grado de Magíster en Investigación, Universidad de los Andes, 2011), p. 24.

${ }^{113}$ Ibíd.

${ }^{114}$ Ibíd. 
del daño que pudo existir lo que caracteriza o agrava la falta, puesto que no cabe distinguir grados de pérdida de confianza ${ }^{115}$.

Otra de las normas que destaca el carácter grave de esta clase de conductas, es el artículo 284 CPen., que contempla el delito de comunicación de secretos de fábrica y que condena a quien haya revelado fraudulentamente dicho secretos de la empresa, en que esté o haya estado contratado, a la pena de reclusión menor en sus grados mínimo a medio o multa de once a veinte unidades tributarias ${ }^{116}$. En este contexto, en el ámbito comparado, autores como Diéguez Cuervo han señalado que la configuración como delictivas de algunas de estas conductas explica por sí sola "la conceptualización de deslealtad" ${ }^{117}$.

\section{La indemnización de perjuicios.}

La divulgación de información confidencial puede provocar perjuicios a la empresa titular de la misma. En tal sentido, creemos que la empresa afectada puede demandar la indemnización por daños o perjuicios al trabajador que ha incumplido un deber de reserva ${ }^{118}$,ya que la consecuencia primera y principal del incumplimiento voluntario, o imputable al deudor, es la reparación del daño ${ }^{119}$. Se dispone así que "todo daño que pueda imputarse a malicia o negligencia de otrapersona debe ser reparado por ésta" (artículo 2329 CC.), como a su vez que "la indemnización de perjuicios comprende el daño emergente y lucro cesante, ya provengan de no haberse cumplido la obligación, o de haberse cumplido imperfectamente, o de haberse tardado el cumplimiento" (cfr. artículo 1556CC.) ${ }^{120}$.

Como decíamos, un pacto o cláusula de confidencialidad contiene una obligación de no hacer. El incumplimiento de esta clase de obligaciones se "resuelve en la de indemnizarperjuicios" si no puede "deshacerse lo hecho" (cfr.

${ }^{115}$ Ibíd.

${ }^{116}$ Sobre esto, véase: Etcheberry Orthusteguy, Alfredo, Derecho penal. Parte especial (3a edición, Santiago de Chile, Editorial Jurídica de Chile, 1998), IV, pp. 278 ss.

${ }^{117}$ DiÉguez Cuervo, Gonzalo, Lecciones de Derecho del Trabajo ( $4^{a}$ edición, Madrid, Marcial Pons, 1995), p. 269

${ }^{118}$ Grisolía, J. A. - Hierrezuelo, R. D., cit. (n. 94), p. 499.

${ }^{119}$ Fueyo LANERI, Fernando, Cumplimiento e incumplimiento de las obligaciones (Santiago de Chile, Editorial Jurídica de Chile, 1991), p. 333.

${ }^{120}$ Recordemos que los requisitos de la indemnización de perjuicios son los siguientes: $i$ ) incumplimiento de una obligación; ii) la existencia de perjuicios; iii) relación de causalidad entre el incumplimiento y los perjuicios; $i v$ ) la imputabilidad del perjuicio, esto es, la culpa o dolo del deudor; v) que no concurra una causal de exención de responsabilidad; y vi) la mora del deudor. Sobre esto, véase Abeliuk Manasevich, René, Las obligaciones ( 5 a edición, Santiago de Chile, Editorial Jurídica de Chile, 2008), II, pp. 814 ss. 
artículo 1555 CC.).A este respecto, cabe tener en cuenta que el principal problema que plantea la preservación del valor de la información empresarial se encuentra en un factor que es consustancial a la misma: su inmateriali$\mathrm{dad}^{121}$. Este rasgo característico de los bienes inmateriales impide que, una vez comunicada, su titular pueda naturalmente excluir su uso por otros sujetos o, lo que es lo mismo, permite que varios sujetos puedan conocerla, trasmitirla y utilizarla simultáneamente y, en consecuencia, determina que su dispersión pueda provocar la disminución, o incluso la anulación de todo su valor ${ }^{122}$.

Por consiguiente, una vez que ha sido divulgada una información reservada y ha sido conocida por terceros, podemos decir que no puede deshacerse lo realizado ${ }^{123}$. De tal manera que procederá el resarcimiento de los perjuicios producidos, ante la imposibilidad de ejecución forzada de la obligación debida, pues no puede restablecerse la situación tal como si no hubiera existido ${ }^{124}$. En efecto, como no hay forma de eliminar la contravención, ella se traduce forzosamente en la indemnización de perjuicios ${ }^{125}$.

Ciertamente, las leyes especiales que contienen deberes de confidencialidad o de tratamiento reservado de información sensible, antes mencionadas, reconducen el incumplimiento de tales obligaciones a través de la indemnización de perjuicios.

La Ley $N^{\circ} 19.039$ prescribe así que el titular de un secreto de empresa que ha sido violado ${ }^{126}$, podrá demandar, entre otras cuestiones, la indemnización

${ }^{121}$ Suñol LuceA, A., cit. (n. 3), p. 28.

${ }^{122}$ Ibíd.

${ }^{123}$ En el ejemplo clásico que Abeliuk Manasevich, R., cit. (n. 120), II, p. 807, da en este caso consiste en el de un artista que se ha comprometido a trabajar en forma exclusiva con un empresario e infringe esta obligación actuando también para otro.

${ }^{124}$ Ibíd., II, pp. 805-806.

${ }^{125}$ Ibíd., II, p. 807.

${ }^{126} \mathrm{La}$ ley de la referencia trata los casos de infracción del secreto de empresa bajo la figura de la "violación del secreto empresarial". El artículo 87 de la Ley $\mathrm{N}^{\circ} 19.039$ define esta figura, como "la adquisición ilegitima del mismo, su divulgación o explotación sin autorización de su titular y la divulgación o explotación de secretos empresariales a los que se haya tenido acceso legitimamente pero con deber de reserva, a condición de que la violación del secreto haya sido efectuada con ánimo de obtener provecho, propio o de un tercero, o de perjudicar a su titular". De la norma recién citada es posible deducir que hay dos clases de violación de secreto empresarial: $i$ ) Adquisición ilegítima del secreto: se precisa que la obtención del secreto se haya llevado a efecto de manera ilícita, sin mediar la autorización de su titular, y en segundo lugar, se requiere que posteriormente que este secreto se divulgue o explote; ii) Adquisición legítima del secreto: se trata de una persona que tuvo acceso legítimo al secreto respecto del que existe deber de reserva, y luego quebranta dicho deber con el ánimo de lograr un provecho propio o de un tercero, o de perjudicar a su titular. Por consiguiente, la persona que infringe este deber es alguien a quien se le ha permitido el conocimiento de información confidencial. En el 
de los daños y perjuicios. Respecto de esta indemnización de perjuicios se establece que podrá determinarse, a elección del demandante, de conformidad con las reglas generales o de acuerdo con una de los siguientes criterios: i) Las utilidades que el titular hubiera dejado de percibir como consecuencia de la infracción; ii) Las utilidades que haya obtenido el infractor como consecuencia de la infracción; y iii) El precio que el infractor hubiera debido pagar al titular del derecho por el otorgamiento de una licencia, teniendo en cuenta el valor comercial del derecho (cfr. el artículo 108 de la Ley $\mathrm{N}^{\circ}$ 19.039 - por remisión del artículo 88 de la misma ley-).

Por su parte, la Ley $\mathrm{N}^{\circ} 19.628$ dispone que en caso que exista un tratamiento indebido de datos de carácter sensible, la persona natural o jurídica privada o el organismo público responsable del banco de datos personales deberá indemnizar el daño patrimonial y moral que causare por tal tratamiento, sin perjuicio de proceder a eliminar, modificar o bloquear los datos de acuerdo a lo requerido por el titular o, en su caso, lo ordenado por el tribunal (cfr. el artículo 23 de la Ley $\mathrm{N}^{\circ} 19.628$ ).

La Ley $\mathrm{N}^{\circ} 18.045$ señala que los socios, administradores, y cualquier persona que en razón de su cargo o posición utilice información reservada de las sociedades clasificadas, para obtener para sí o para otros, ventajas económicas de cualquier tipo ${ }^{127}$, deberán devolver a la caja social del emisor toda utilidad que hubieren obtenido, valiéndose de la información reservada. Asimismo, toda persona que se sintiere perjudicada por infracción a lo dispuesto precedentemente tendrá derecho a demandar indemnización de perjuicios en contra de las personas indicadas (cfr. el artículo 85 de la Ley $\mathrm{N}^{\circ} 18.045$ ).

A su vez, en materia de información privilegiada tratada en el título $21^{\circ}$ de la Ley $\mathrm{N}^{\circ} 18.045$, se dispone que toda persona perjudicada por actuaciones que impliquen infracción de dicha normativa -entre las que se encuentra el deber de reserva de dicha información-, tendrá derecho a demandar indemnización en contra de las personas infractoras (cfr. el artículo 172 de la Ley

ámbito laboral, dicha persona puede ser un trabajador pues precisamente para efectos que lleve a cabo su prestación de servicios, el empleador le concede o transmite antecedentes o información para que desarrolle la labor contratada. Se exige asimismo que la persona que incumple el deber de reserva tenga un ánimo de "obtener provecho, propio o de un tercero, o de perjudicar a su titular". No se requiere, según se detalla, que se haya producido dicho provecho o perjuicio, sino que resulta suficiente la intención de provocar alguno de ellos.

${ }^{127}$ Con la aprobación de las tres cuartas partes de los directores en ejercicio podrá darse el carácter de reservado a ciertos hechos o antecedentes que se refieran a negociaciones aún pendientes que al conocerse puedan perjudicar el interés social. Tratándose de emisores no administrados por un directorio u otro órgano colegiado, la decisión de reserva debe ser tomada por todos los administradores (cfr. inciso $3^{\circ}$ artículo 10 de la Ley $\left.\mathrm{N}^{\circ} 18.045\right)$. 
$\left.N^{\circ} 18.045\right)$. Se establece asimismo que tales personas infractoras, deberán entregar a beneficio fiscal, cuando no hubiere otro perjudicado, toda utilidad o beneficio pecuniario que hubieren obtenido a través de transacciones de valores del emisor de que se trate (cfr. el artículo 172 de la Ley $\mathrm{N}^{\circ} 18.045$ ).

Por último, es necesario subrayar que para la procedencia de la indemnización por daños y perjuicios será necesario que la divulgación indebida de información haya provocado un perjuicio real en la empresa ${ }^{128}$.Estos daños provocados al poseedor de los secretos divulgados ilegítimamente se producen principalmente por la desvalorización de dichos conocimientos como consecuencia de su difusión ${ }^{129}$. La determinación de tales perjuicios para los tribunales, implicará la difícil tarea de ponderar una serie cuestiones hecho ${ }^{130}$. Siguiendo a Mitelman y Zuccherino, entre los factores a considerar para tales efectos, es posible señalar, entre otros: las inversiones realizadas para lograr la información confidencial, la disminución de las ganancias sufridas, las ganancias logradas por el infractor, y el grado de divulgación de los conocimientos reservados entre empresas de la competencia ${ }^{131}$.

\section{CONCLUSIONES}

$1^{\circ}$ La información reservada de una empresa no se incardina necesariamente dentro del secreto de empresa de la Ley $N^{\circ} 19.039$, que se circunscribe en exclusiva a aspectos industriales. En efecto, existen disposiciones legales que otorgan de manera imperativa el carácter de reservado a materias que se refieren a aspectos íntimos de las personas (Ley 19.628), cuestiones referidas a las cuentas bancarias (Ley general de bancos), e información de sociedades clasificadas (Ley de mercado de valores). Asimismo, se puede conceder a petición de parte el carácter de reservado -en un proceso de libre competencia- a aquellos aspectos cuya revelación pueda afectar negativamente el interés competitivo de su titular (Decreto-ley $\mathrm{N}^{\circ} 211$ ).

$2^{\circ}$ En el ámbito laboral, la cláusula de confidencialidad puede ser definida como un acuerdo bilateral suscrito entre empleador y trabajador, cuyo objeto consiste en imponer a este último la obligación de que determinada información, de la cual tome conocimiento con ocasión de su labor en la empresa, sea mantenida oculta a terceros.

$3^{\circ}$ Una de las virtudes de mayor relevancia de los pactos de confidencialidad consiste en determinar las materias que revisten el carácter de secretos

\footnotetext{
${ }^{128}$ Sobre el perjuicio, como elemento de la responsabilidad civil, véase: ABELIUK Manasevich, R., cit. (n. 120), II, pp. 814 ss.

${ }^{129}$ Mitelman, C. - Zuccherino, D., cit. (n. 1), p. 54.

${ }^{130}$ Ibíd.

${ }^{131}$ Ibíd.
} 
y sobre las que, por lo tanto, debe mantenerse la reserva. Y es que si no existe un pacto donde se precise las materias objeto de reserva, pueden surgir dudas en cuanto a cuáles tendrían la condición de secreto, y por tanto, deben ser objeto de protección.

$4^{\circ}$ Los pactos o cláusulas de confidencialidad pueden suponer la afectación de derechos constitucionales de los trabajadores, en particular la libertad de trabajo y la libertad de expresión. Para resolver esta posible colisión de derechos, nos parece necesario -siguiendo el criterio de la Dirección del Trabajo- aplicar el principio de proporcionalidad. Para ello resulta pertinente desarrollar los tres sub principios del mismo, a saber: principio de adecuación o idoneidad, el principio de necesidad, y el principio de proporcionalidad en sentido estricto.

$5^{\circ}$ Desde el punto de vista del principio de idoneidad, la justificación de una cláusula de confidencialidad se debe fundamentar en la protección de una ventaja competitiva, en el cumplimiento de un imperativo legal, y en la protección del derecho fundamental consistente en el respeto y protección de la vida privada de la persona del empleador y su familia.

$6^{\circ}$ La necesidad de la confidencialidad estará determinada por el tipo de información y el puesto de trabajo que requiera estar en contacto con ella. Así, los cargos de mayor jerarquía, que podrían ser calificados de exclusiva confianza, seguramente estarán en conocimiento de antecedentes confidenciales. Con todo, tratándose de un secreto de empresa a los que se refiere la Ley $\mathrm{N}^{\circ} 19.039$, la importancia de mantener su reserva se extenderá a todos los trabajadores, más allá del grado jerárquico, que estén trabajando en el desarrollo de la posible invención.

$7^{\circ}$. El aspecto valioso del secreto empresarial consiste en que su titular posee una ventaja en relacón a un competidor. Si la cláusula de confidencialidad se ciñe expresamente a aquellos aspectos relativos a la ventaja competitiva, su establecimiento sería proporcionalmente justificado frente a los derechos de la libertad de trabajo y la libertad de expresión del trabajador. Por el contrario, si en una cláusula de confidencialidad se incluyen cuestiones que son de conocimiento público o materias que se han integrado en la personalidad profesional del trabajador, ésta carecería de la justificación necesaria toda vez que se estaría dando el carácter de confidenciales a aspectos que en realidad no lo son.

$8^{\circ} \mathrm{Si}$ la cláusula de confidencialidad se suscribe en el marco de un contrato de trabajo, éste constituye la causa para que la empresa le transmita al trabajador información confidencial que sea requerida para prestar sus servicios, y de ahí que surja la necesidad para la empresa de estipular un deber de reserva. Por tales motivos, consideramos que este tipo de cláusula tiene naturaleza laboral, y no civil. Tal criterio lo mantenemos aun cuando se trate de cláu- 
sulas que se suscriban para regir no sólo vigente el contrato de trabajo, sino también con posterioridad al cese de éste, toda vez que el fundamento en ambos supuestos es el mismo: la relación laboral que liga o ligó a las partes.

$9^{\circ}$ El pacto de confidencial implica para el trabajador una obligación de no hacer, consistente en la abstención de divulgar la información que se entiende reservada.Este pacto se infringirá cuando el trabajador obligado a guardar reserva transmite la información objeto del secreto. El incumplimiento de este tipo de cláusula se podrá reconducir por la empresa a través de dos vías. La primera, es el despido, y la segunda, la indemnización por daños y perjuicios.

\section{BiBLIOGRAFÍA}

Abeliuk Manasevich, René, Las obligaciones ( 5 a edición, Santiago de Chile, Editorial Jurídica de Chile, 2008).

Alexy, Robert, Derechos fundamentales, ponderación y racionalidad, en Revista Iberoamericana de Derecho Procesal Constitucional, 11(2011).

Alonso Olea, Manuel - Casas Baamonde, María Emilia, Derecho del Trabajo $\left(24^{\mathrm{a}}\right.$ edición, Madrid, Civitas, 2006).

Arnold, Rainer - Martínez Estay, José Ignacio - Zúñiga Urbina, Francisco, El principio de proporcionalidad en la jurisprudencia del Tribunal Constitucional, en Estudios Constitucionales, 10 (2012) 1.

Bertelsen Repetto, Raúl, Datospersonales: propiedadprivada, libre iniciativa particulary respeto a la vida privada, en W AHL, Jorge (editor), Tratamiento de datos personales y protección de la vida privada. Estudios sobre la Ley $N^{\circ} 19.628$ sobreprotección de datos de carácter personal (Santiago de Chile, Cuadernos de Extensión Jurídica, 5, Facultad de Derecho, Universidad de los Andes, 2001).

BreARley, Kate - BloCh, Selwyn, Employment Covenants and Confidential Information . Law Practice and Technique ( $3^{a}$ edición, Londres, Tottel Publishing, 1999).

Cabanellas de las Cuevas, Guillermo, Régimen jurídico de los conocimientos técnicos. "Knowhow" y secretos comerciales e industriales (Buenos Aires, Heliasta, 1984).

Castro García, Juan David, La propiedad industrial (Bogotá, Universidad Externado de Colombia, 2009).

De Val Tena, Ángel, Los trabajadores directivos de la empresa (Navarra, Aranzadi, 1999).

Diéguez Cuervo, Gonzalo, La fidelidad del trabajador en Ley de contrato de trabajo (Pamplona, Ediciones Universidad de Navarra, 1969).

Diéguez Cuervo, Gonzalo, Lecciones de Derecho del Trabajo ( $4^{a}$ edición, Madrid, Marcial Pons, 1995).

Etcheberry Orthusteguy, Alfredo, Derecho penal. Parte especial (3 $3^{a}$ edición, Santiago de Chile, Editorial Jurídica de Chile), IV.

Fueyo Laneri, Fernando, Cumplimiento e incumplimiento de las obligaciones (Santiago de Chile, Editorial Jurídica de Chile, 1991).

Gómez Segade, José Antonio, El secreto industrial. Concepto y protección (Madrid, Tecnos, 1974).

González Ortega, Santiago, El conflicto entre los derechos fundamentales del trabajador y la libertad de empresa: El necesario tránsito desde el juicio de proporcionalidad 
al juicio de ponderación, en Revista Chilena de Derecho del Trabajo y de la Seguridad Social, 3 (2012) 6.

Grau Gabrielli, Daniela - Parker Jiménez, Jorge - Uzal Castro, José, Confidencialidad de la información reservada en la relación laboral (Santiago de Chile, tesis para optar al grado de Licenciado en Ciencias Jurídicas y Sociales, Universidad de Chile, 2007).

Grisolía, Julio Armando - Hierrezuelo, Ricardo Diego, Derechos y deberes en el contrato de trabajo (Buenos Aires, AbeledoPerrot, 2010).

Irureta Uriarte, Pedro, La falta de probidad como causa de extinción del contrato de trabajo, en Pereira, Rafael - CaAmaño, Eduardo (coordinadores), Estudios de Derecho del Trabajo y de la Seguridad Social. Doctrina chilena y extranjera (Santiago de Chile, AbeledoPerrot - LegalPublishing, 2012), II.

Irureta Uriarte, Pedro, Vigencia del principio de la buena fe en el Derecho del Trabajo chileno, en Ius et Praxis, 17 (2011) 2.

Lois BASTIDA, Fátima, La protección del inventor asalariado (Madrid, Civitas, 2000).

López Santa María, Jorge, Los contratos. Parte general ( $5^{a}$ edición, Santiago de Chile, AbeledoPerrot - LegalPublishing, 2010).

Martín Valverde, Antonio - Rodríguez-Sañudo Gutiérrez, Fermín - García Murcia, Joaquín, Derecho del Trabajo (15ª edición, Madrid, Tecnos, 2006).

Melis VAlenCia, Christian, Los derechos fundamentales de los trabajadores como limites a lospoderes empresariales (Santiago de Chile, AbeledoPerrot - LegalPublishing, 2009).

Mitelman, Carlos O. - Zuccherino, Daniel, Protección juridica de la información confidencial y de datos cientificos (Buenos Aires, LexisNexis, 2007).

Moliner Ruiz, María, Diccionario de uso del español (Madrid, Gredos, 2002).

Munita Luco, Enrique, El perjuicio económico como elemento de configuración de la gravedad del despido (Santiago de Chile, tesis para optar al grado de Magíster en Investigación, Universidad de los Andes, 2011).

Nogueira Guastavino, Magdalena, Pacto laboral de no competencia postcontractual (Madrid, McGraw-Hill, 1998).

SAlgado Miranda, Jorge, La cláusula de confidencialidad en el contrato individual de trabajo (Quito, tesis para optar al grado de doctor en Derecho, Universidad Internacional SEK del Ecuador, 2006).

Schmitz Vaccaro, Christian, Protección del secreto empresarial, en Contreras, Rodrigo (coordinador), Jornadas Chileno-Uruguayas de Derecho Comercial (Santiago de Chile, Librotecnia, 2011).

Sierra Herrero, Alfredo, Aspectos laborales del gerente: representación empresarial y desahucio, en Revista de Derecho de la Empresa, 20 (2009).

Suñol Lucea, Aurea, El secreto empresarial. Un estudio del artículo 13 de la ley de competencia desleal (Pamplona, Thomson Reuters, 2009).

Thayer Arteaga, William - Novoa Fuenzalida, Patricio, Manual de Derecho del Trabajo (4a edición, Santiago de Chile, Editorial Jurídica de Chile, 2007), III y IV.

Ugarte Cataldo, José Luis, Derecho, Trabajo y privacidad (Santiago de Chile, AbeledoPerrot -LegalPublishing, 2011).

Ugarte Cataldo, José Luis, Privacidad, trabajo y derechos fundamentales, en Estudios Constitucionales, 9 (2011) 1.

Vázquez Vialard, Antonio, Derecho del Trabajo y de la Seguridad Social (Buenos Aires, Astrea, 1996). 